\title{
REVIEW
}

\section{Background and Current Treatment of Squamous Cell Carcinoma of the Anus}

Rob Glynne-Jones · Waqar Saleem • Mark Harrison · Suzy Mawdsley •

Marcia Hall

Received: April 20, 2016 / Published online: August 1, 2016

(C) The Author(s) 2016. This article is published with open access at Springerlink.com

\section{ABSTRACT}

In this review, a summary of our current understanding of squamous cell carcinoma of the anus (SCCA) and the advances in our knowledge of SCCA regarding screening, prevention, the role of the immune system, current treatment and the potential for novel targets are discussed. The present standard of care in terms of treatment is 5-fluorouracil (5-FU) and mitomycin C (MMC) concurrently with radiation, which results in a high level of disease control for small early cancers. Preservation of the anal sphincter is achieved in the majority, although anorectal function is often impaired. Although evidence from prospective studies to support a change in the treatment strategy is lacking, patients with HPV-negative SCCA appear to be less responsive to chemoradiation (CRT) and relapse more frequently. In contrast,

Enhanced content To view enhanced content for this article go to http://www.medengine.com/Redeem/ CED4F060266B3651.

R. Glynne-Jones $(\bowtie) \cdot$ W. Saleem · M. Harrison ·

S. Mawdsley · M. Hall

Centre for Cancer Treatment, Mount Vernon

Hospital, Northwood, Middlesex, UK

e-mail: rob.glynnejones@nhs.net
HPV-positive tumours usually fare better, but oncological outcomes are modified by smoking and immune incompetence. There is current interest in escalating the radiotherapy dose for larger, more advanced tumours, and de-escalating treatment for HPV-positive tumours. The use of novel immunological treatments to target the underlying different molecular pathways of HPV-positive cancers is exciting.

Keywords: Anal carcinoma; Anal intraepithelial neoplasia; Chemoradiation; Chemotherapy; Combined modality; Immunotherapy; Local recurrence; Radiotherapy; Squamous cell carcinoma of the anus

\section{INTRODUCTION}

Squamous cell carcinoma of the anus (SCCA) is a rare malignancy which accounts for only $2-4 \%$ of all lower alimentary tract malignancies [1]. The incidence of SCCA has been rising and is now approximately 1.8 per 100,000 , accounting for $>7000$ men and 
women per year in the US. Data from Public Health England show that the incidence of SCCA increased $126 \%$ in women and $69 \%$ in men in the UK during the period 1990-1994 to 2006-2010 [2].

Due to its rarity, few high-quality randomised controlled trials are available to guide our decision-making. SCCA generally presents as a localised disease with a low risk of metastatic disease unless CRT fails. Locoregional failure is the predominant pattern of relapse [3] and is responsible for most SCCA-related deaths, making local control (LC) the primary aim of treatment and the primary endpoint in some trials.

Overall survival (OS) has usually been a secondary endpoint in the trials. OS may not, however, be the most useful endpoint because OS requires large numbers of patients for sufficient events (such large numbers of patients with rare cancers are even more difficult to recruit), and there are competing risks of death in an elderly population. Also, the availability and feasibility of subsequent effective and specialist surgical salvage have not been uniform. These observations partly explain why the overall 5-year survival appears very similar in trials: $78 \%$ in the MMC arm of the Radiotherapy Therapy Oncology Group RTOG 98-11 trial [4], 71\% in the CRT-alone arms of the Action Clinique Coordonnées en cancérologie Digestive (ACCORD-03) [5] and $79 \%$ in the MMC arm of the Anal Cancer Trial (ACT II) [6]. Preservation of the anal sphincter is achieved in the majority, although with doses of 50-60 Gy (as used in the phase III trials), anorectal function is often impaired [7]. The outcomes for patients with larger cT3/T4 cancers are less favourable. In the RTOG 98-11 trial, patients with cT2/T3N0 had a 5-year disease-free survival (DFS) of 70\%, which fell to $38 \%$ for cT3N1-3 and only $31 \%$ for cT 4 N1-3
[8]. In ACT II, patients with cT3/T4 cancers and/ or nodal metastases had a 3-year progression-free survival (PFS) of 63\% [6] (see Table 1).

The randomised trials involving SCCA patients examined three cytotoxic agents as radiotherapy partners (5-fluorouracil, mitomycin $\mathrm{C}$ and cisplatin). Although the schedules are similarly timed (often days 1-5 and days 29-33), the number of doses and the total $\mathrm{mg}$ delivered in these regimens have not been consistent (Table 2). CRT using 5-FU and MMC, which has been tested in several randomised trials $[6,9-12]$, is the standard of care which results in a high level of disease control for cT1/T2 cancers and is currently recommended in European and US guidelines $[13,14]$.

Although there is a clear need for more effective treatments in more advanced cT3/T4 and/or node-positive cancers, additional strategies examined in trials have so far failed to improve outcomes, in part because the CRT component was not always optimised. Randomised phase III trials by the RTOG 98-11 [12], the ACCORD-03 phase III trial [5] and the ACT II trial failed to show any additional benefit in terms of PFS by increasing the radiotherapy boost dose, or replacing MMC with cisplatin during CRT [6]. Nor has additional cisplatin-based chemotherapy given as induction prior to CRT $[5,12]$ or as maintenance chemotherapy after CRT [6] improved outcomes.

There have been some intriguing developments in the past 3 years in terms of our understanding of the molecular biology and processes which lead to SCCA, and the vital role of the immune system. There have also been some notable successes in prevention, imaging (e.g. MRI for staging delineation and restaging) and treatment. This paper will discuss these 


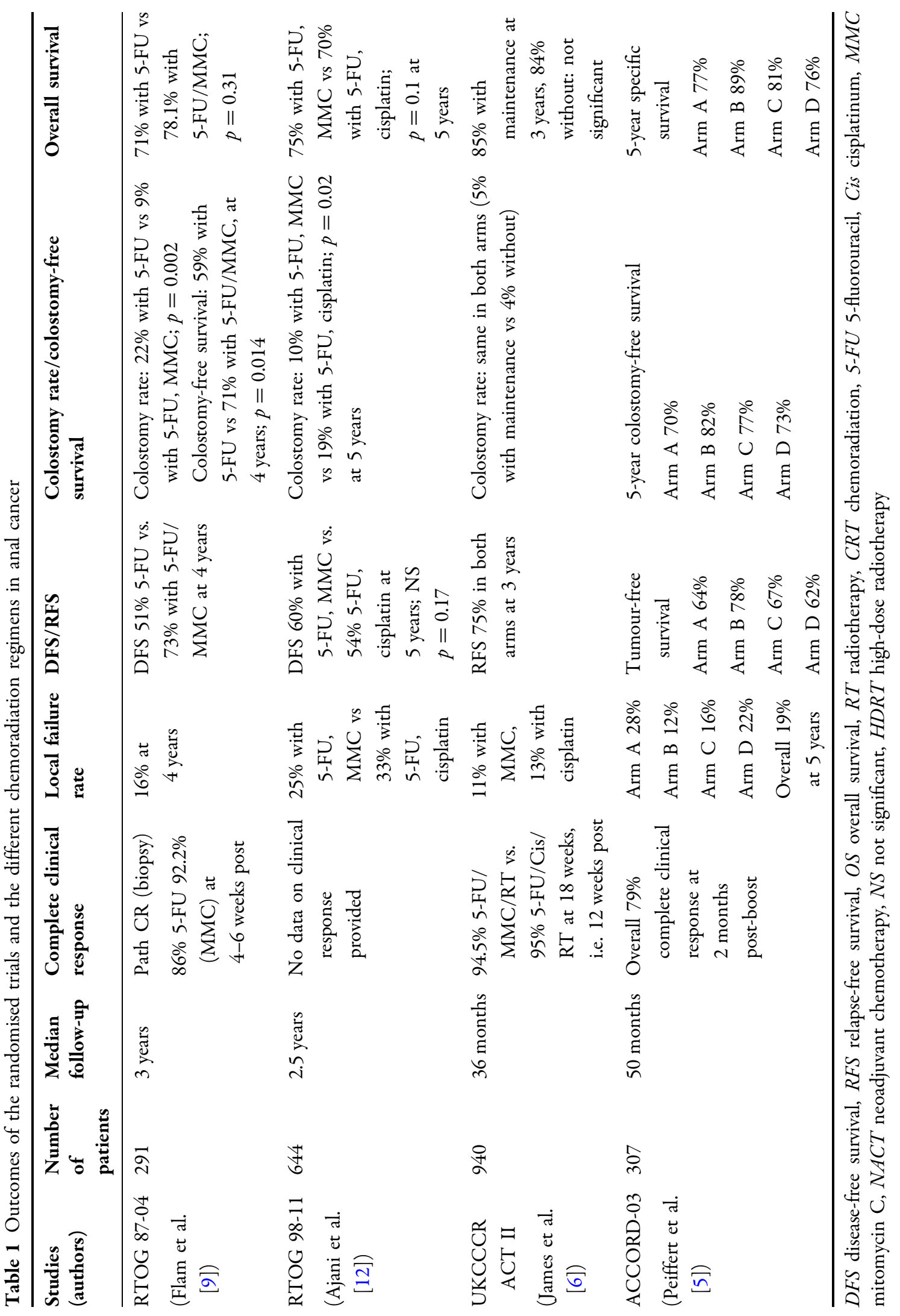




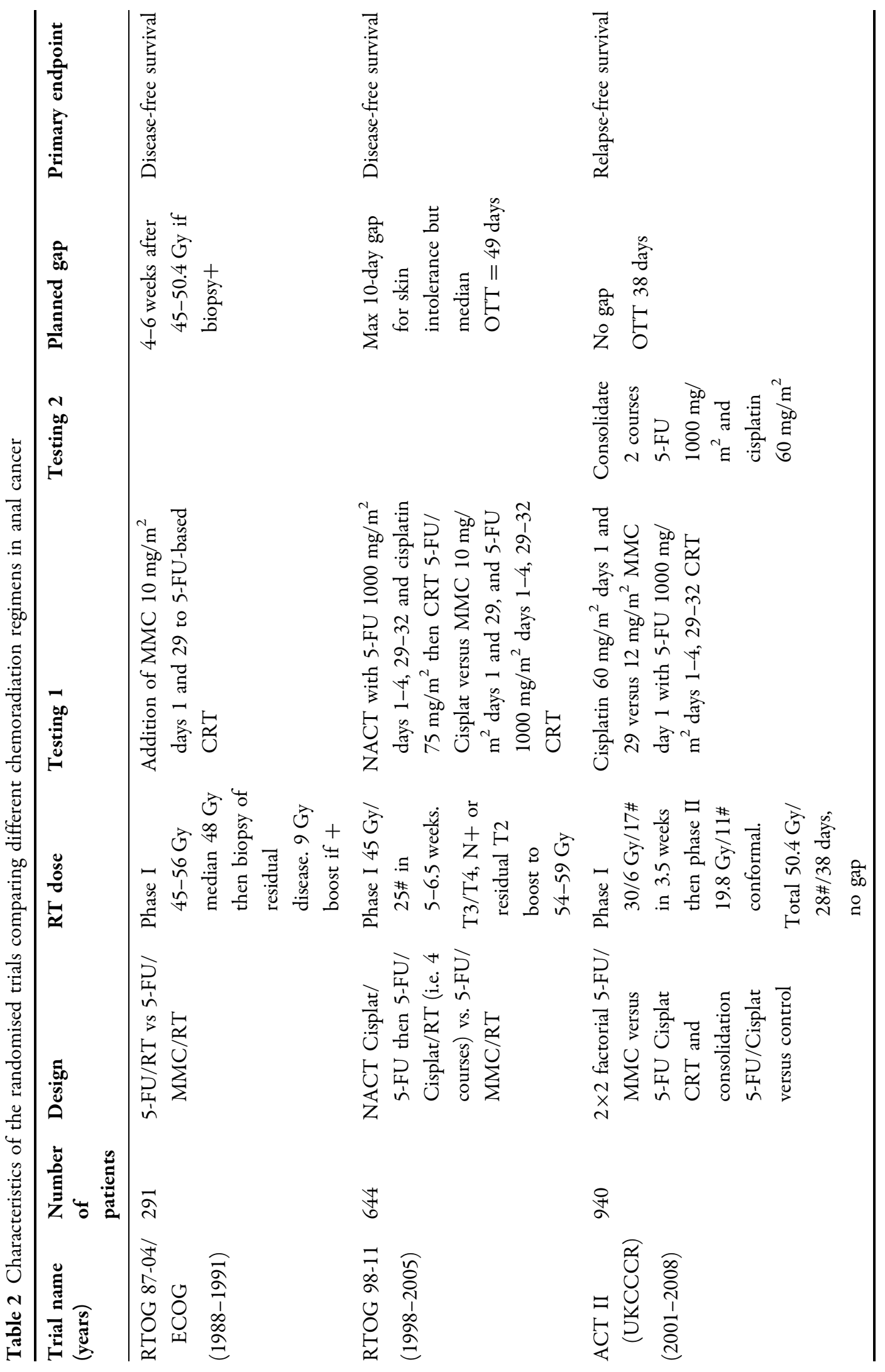




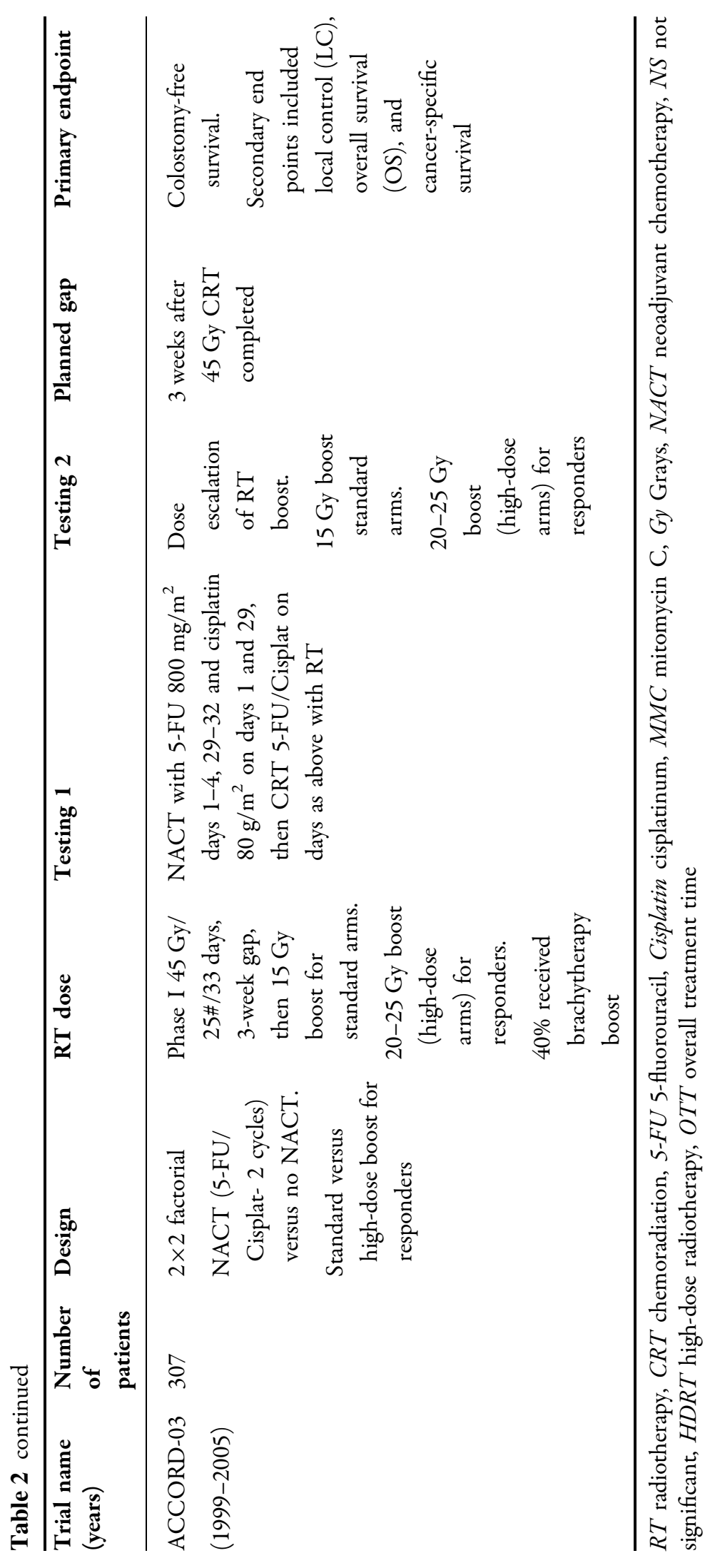


advances, but limit its discussion to SCC arising in the anal canal and margin, and ignore other biologically distinct anal tumours such as melanomas, neuroendocrine tumours, adenocarcinomas, lymphomas and GIST tumours.

This article is based on previously conducted studies and does not involve any new studies of human or animal subjects performed by any of the authors.

\section{EPIDEMIOLOGY AND PATHOGENESIS}

The incidence of SCCA has been increasing over the past three decades-most markedly in women. The natural history is usually slow, with patients complaining of symptoms for months if not years, and distant metastases are uncommon at presentation [10, 15, 16]. Hence, SCCA is usually amenable to locoregional CRT, which is a potentially curative treatment.

\section{Risk Factors and Aetiology}

The role of human papillomavirus (HPV) in the aetiology of SCCA was described more than 20 years ago [17]. SCCA is associated with HPV in $80-90 \%$ of cases $[18,19]$ (usually in Europe HPV16 or HPV18 subtypes), as is the precursor high-grade anal-intraepithelial neoplasm (AIN). Women with previous HPV-related cervical, vulvar or vaginal diseases are at a higher risk of developing SCCA.

A 30-fold higher risk of SCCA is observed in human immunodeficiency virus (HIV)-infected patients compared to the general population [20]. Other recognised risk factors for the development of SCCA include the long-term use of immunosuppressants such as azathioprine and corticosteroids, and autoimmune disorders such as systemic lupus. Transplant recipients have a tenfold risk compared to the general population. Social deprivation is implicated [21]. A history of receptive anal intercourse increases the risk, but is not a necessary condition. Cigarette smoking is a potent risk factor [22, 23]. Cigarette smoking may also have a role in the persistence of HPV infection, and potentially influences outcomes from treatment. Even in the context of HIV, patients with SCCA who smoke also appear to have a worse overall survival than nonsmoking patients [24].

Although previously discounted, recent data also suggest that there is a higher incidence of SCCA in Crohn's disease, an earlier age of presentation and poorer outcomes [25]. There is no clear association with any dietary habits or the presence of haemorrhoids [26, 27]. Men who have sex with men (MSM) have a high incidence of SCCA:(35 per 100,000, which increases to $75-135$ per 100,000 with HIV seropositivity. The incidence is also higher among HIV-seropositive women [28].

Substantial evidence implicates HPV in the aetiology of SCCA. HPV has been identified in $84.5 \%$ of cases in a meta-analysis examining HPV prevalence in AIN and SCCA from 93 studies conducted in four different continents [18]. HPV16 and HPV18 appear to be the two commonest genotypes detected. Prospective data also link HPV seropositivity to the risk of subsequent SCCA [29]. HIV-positive and HIV-negative homosexual men are more likely than the general population to be infected with HPV, often with more than one subtype [30], and are more likely to demonstrate HPV-associated AIN.

HPV is virtually endemic, with a lifetime risk of acquiring genital HPV at least once of $>80 \%$ [31]. HPV infects squamous cells at the deep aspect of the perianal skin or anorectal mucosa 
by way of ulceration or trauma to the superficial layers. HPV overrides the cell's normal machinery and DNA synthesis, replicating itself and releasing further HPV into the surrounding epithelium. Individuals infected with HPV are asymptomatic and hence unaware of the infection. Most of those infected will clear the virus within 2 years, without harm to the host. Factors which contribute to the delayed clearance of anal HPV in women include douching, cigarette smoking, and performing anal sex [32], but there are no recognised interventions to treat active HPV infection. Anal intercourse and a high lifetime number of sexual partners increase the risk of persistent HPV infection in men and women. It is unknown why virus persistence and chronic infection, which later lead to HPV-induced SCCA, develop in a few patients. Not all persistent infections cause disease. Our impression is that patients with HPV-associated SCCA tend to present, on average, a decade younger than patients with HPV-negative cancer.

HPV-positive cell lines appear intrinsically more radiosensitive, with clear differences in cell cycle check-point and apoptotic signalling pathways, as well as reduced DNA repair abilities. This finding may be partly explained by the association of HPV with the viral proteins E6 and E7, which integrate into the host DNA [33] and inhibit normal antiviral immune mechanisms but are insufficient on their own for malignancy. E6 and E7 inhibit the activity of the tumour-suppressor proteins p53 (in the host) and pRb (in normal cells) [34], creating aberrant apoptosis as a first step to allowing cells to become immortal. The E7 protein binds and inactivates the retinoblastoma $(\mathrm{Rb})$ protein. The role of $\mathrm{Rb}$ is to regulate E2F (a transcription factor controlling cell cycle progression). Inactivation of $\mathrm{Rb}$ releases the brakes from E2F (see Fig. 1), so cell cycle progression is unchecked via the

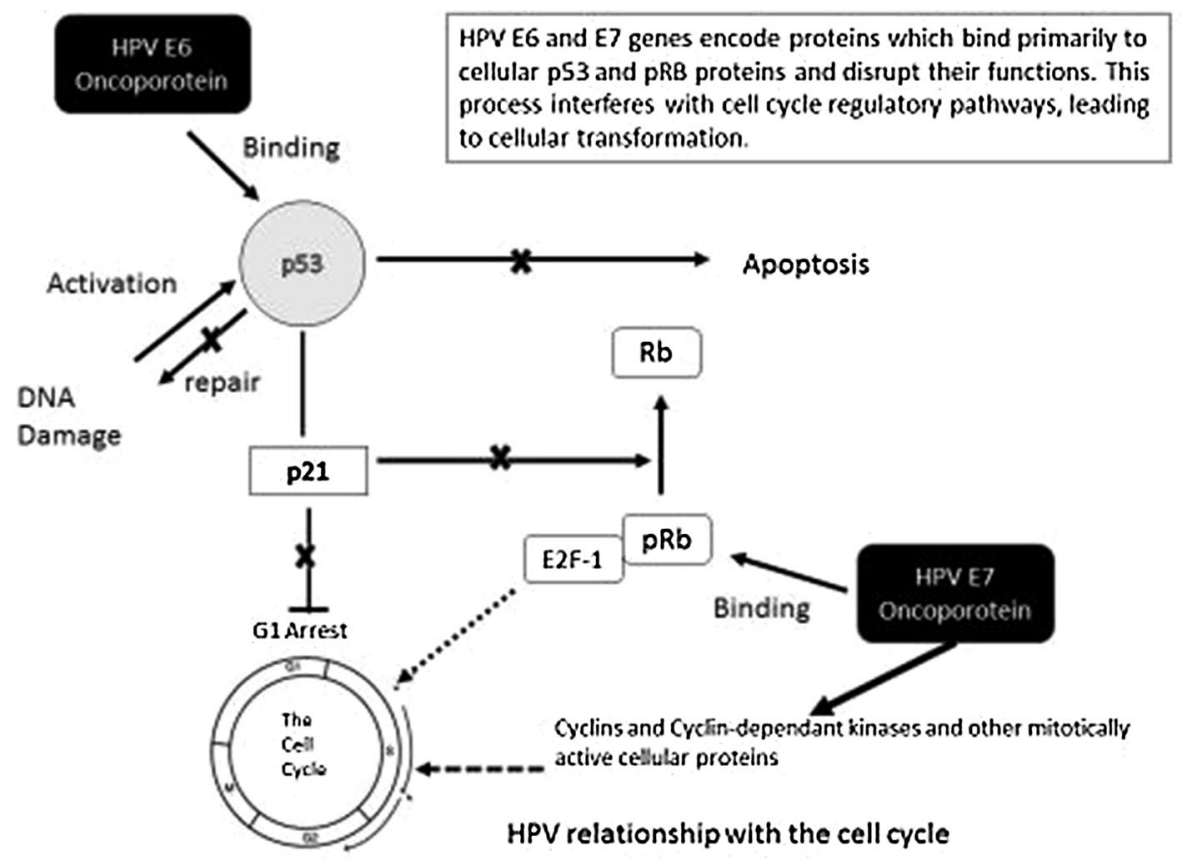

Fig. 1 Illustrating the relationship of HPV E6 and E7 and the cell cycle 
activation of p16, a cyclin-dependent kinase inhibitor that functions as a check-point inhibitor.

\section{p16INK4A (p16)}

p16 (also known as cyclin-dependent kinase inhibitor 2A) is a tumor-suppressor protein. Positive immunohistochemical staining (IHCS) for p16 is used as a surrogate for HPV involvement, based on the high concordance between these two biomarkers. However, p16 IHC analysis cannot distinguish between HPV-16, the most common HPV genotype found in squamous cell carcinoma of the head and neck (SCCHN), and other rarer and more aggressive genotypes. However, better responsiveness to radiation does not wholly explain the improved outcomes, as HPV $+/ \mathrm{p} 16+$ SCCHN cases treated with surgery alone appear to demonstrate improved RFS and OS [35].

\section{Anal Intraepithelial Neoplasia}

SCCA may arise from a precursor dysplastic lesion-anal intraepithelial neoplasia (AIN) also known as anal squamous intraepithelial lesions (SILs). The concept of intraepithelial pre-cancer was first described in the context of cervical cancer in 1888 by Sir John Thomas. There is an ongoing debate arguing that the traditional three-tiered grading of AIN1, AIN2 and AIN3 should be replaced by a more reproducible two-tiered system (effectively high grade versus low grade). AIN I is considered a low-grade squamous intraepithelial lesion (LSIL or LGAIN). AIN 2 and 3 are rated as a high-grade squamous intraepithelial lesion (HSIL or HGAIN). HSIL or HGAIN/AIN3 is increasingly being identified during the screening of immunosuppressed patients for anal dysplasia, but the prevalence of AIN in the general population is low [36]. It may approach $20 \%$ in HIV + men [37], and even higher in MSMs. Progression from AIN to invasive malignancy is uncommon in immunocompetent patients [38] but more frequent in immunosuppressed patients [39] and older patients. Progression is also influenced by HIV seropositivity, a low CD4 count and the serotype of HPV infection $[40,41]$. These groups have a high risk of high-grade AIN and more rapid progression to invasive cancer [42].

The natural history of progression from AIN to invasive carcinoma in HIV-positive individuals has changed with effective treatment using highly active antiretroviral therapy (HAART). HIV-positive individuals can expect to live longer and thus have longer exposure with their immune suppression to the effects of HPV. Hence, SCCA is the commonest malignancy in HIV-positive individuals in the United States [43].

\section{PREVENTION}

Prevention can be divided into primary and secondary. Primary prevention aims to prevent HPV infection persisting long-term. Secondary prevention relies on methods of identifying pre-cancerous lesions (AIN) or very early stage cancers with appropriate definitive treatment. Two available vaccines-a bivalent HPV 16/18 vaccine (Cervarix) and a quadrivalent HPV 6/11/ $16 / 18$ vaccine (Gardasil) - have been used in the prevention of cervical, vaginal and vulvar warts/ AIN/early cancer. There is now also a 9-valent vaccine (Gardasil 9) in use [44]. The HPV types detected in SCCA are included in the 9-valent vaccine, so it should in future effectively prevent SCCA if administered to boys and girls prior to the onset of sexual activity. 


\section{HPV Vaccination}

Safe and effective vaccines against HPV-16 and HPV-18 infection have been commercially available for a decade. Since most SCCA and pre-cancerous lesions are attributed to human papillomavirus (HPV) infection, prevention of HPV infection reduces the risk of SCCA/AIN. Vaccination against HPV-16 and HPV-18 has been shown to be highly effective in preventing cervical dysplasia and thus cervical cancer [45]. Recently, the quadrivalent HPV vaccine (effective against the four most common HPV types: $6,11,16$ and 18 ) has also been shown to be highly effective in preventing HPV-16 and HPV-18 associated anal dysplasia [46]. This double-blind study reported a reduction in the rates of AIN in healthy MSM of 54.2\% (95\% CI 18.0-75.3) in the intention-to-treat population and $74.9 \% \quad(95 \% \quad$ CI $8.8-95.4)$ in the per-protocol efficacy population [46]. A large proportion of SCCA cases could theoretically be prevented in the future.

However, there is a question regarding the durability of the protection. One study in MSM with treated high-grade AIN who received the quadrivalent HPV vaccine reported a significantly reduced risk of recurrence compared with those who did not receive the vaccine, which appears to be durable for at least 2 years. However, 12/88 vaccinated MSM (13.6\%) still developed a recurrence, so it is not $100 \%$ effective in this population. The antibody response may attenuate over time [47]. In women, the duration may be more prolonged [48].

Although HPV vaccines may prevent future HPV infection, they do not eliminate existing high-risk HPV infections or treat patients who already have SCCA. The efficacy of the two available vaccines against oncogenic HPV is more than $90 \%$ for both cervical and anal intraepithelial neoplasia. However, there is no HPV vaccination programme for boys in the UK. Spillover via herd immunity may offer some protection to males, but it is anticipated that incidence rates may rise in menparticularly men who have sex with men (MSM)-because of this policy. Therapeutic vaccines targeting the E6/E7 oncogenes or the cellular pathways which they drive might do so [49]. A study using a vaccine against the HPV-16 oncoproteins E6 and E7 has reported clinical responses in women with HPV-16-positive, G3 vulvar intraepithelial neoplasia [50]. However, these agents may also indirectly improve natural immunity.

In summary, HPV vaccination of girls and boys in early adolescence might be expected to prevent SCCA in the general population and among future cohorts of persons infected with HIV/MSM, but prophylactic vaccines are unlikely to affect people already infected with HIV and exposed to oncogenic HPV. However, it also remains unclear how long the immune response will continue to give protection.

\section{Screening}

SCCA is rare in the general population, but similarities in both the epidemiology and aetiology between squamous cancers of the cervix and the anus have raised the suggestion that similar screening programmes in appropriate high-risk groups could reduce the incidence of SCCA. Anal cytology and high-resolution anoscopy (HRA) in asymptomatic patients are feasible and are currently performed in many clinics in the USA [51, 52], although practices vary widely. Any identified internal high-grade AIN can be treated with infrared coagulation, and external high-grade AIN with excision, imiquimod or topical 5-fluorouracil (although recurrence is 
not uncommon in immunocompromised populations where HPV infection tends to persist). In HIV-positive patients, electrocautery appears more effective than imiquimod or topical fluorouracil in the treatment of AIN, but recurrence rates were again substantial [53].

However, we are not aware of mature data from any long-term controlled trials to evaluate screening for SCCA. Hence, the optimal methods of screening remain under debate. The value of screening for SCCA using anal cytology [54] or high-resolution anoscopy [55] is currently being investigated, mainly in groups with major risk factors such as MSM, patients with HIV, HIV - women with a history of anal intercourse or other HPV-related anogenital malignancies, and patients immunosuppressed as a result of solid-organ transplantation, but it remains rarely performed by general surgeons [56]. The hypothesis of benefit is based on the favourable results obtained in cervical cytology (Pap smear) screening. These tests may detect dysplasia before it develops into invasive cancer and pre-cancerous lesions (AIN). Yet, because it is unusual for AIN/HSIL to progress to cancer even without treatment, the specificity of anal cytological screening may be too low.

HPV16 E6 seropositivity is relatively common some years before the diagnosis of SCCA, and could be used as a screening tool. In a recent study of patients with anogenital cancers, HPV16 E6 seropositivity was present in plasma in $7 / 24$ individuals (29.2\%) 3-8 years before they developed SCCA compared with $0.6 \%$ of controls (4/718) who remained cancer-free [57]. More specific targets, such as high-risk HPV genotypes' DNA or RNA or E6 seropositivity, may be a more effective component of future screening programmes. But, as we have already remarked above, no randomised control study has yet demonstrated the advantage of screening in these high-risk populations, and we are currently not aware of any national programmes involved in widespread screening via Pap smear testing for SCCA.

Finally the frequency of further surveillance, once AIN is identified, remains controversial. Some recommend a clinical review every 12 months in HIV-negative patients with low-grade AIN, and increasing the frequency to 4-6 months in HIV-infected or patients with high-grade AIN [41]. Others use clinical and cytological screening every 3 months in patients with high-grade AIN [58].

\section{PRESENTATION AND DIAGNOSIS}

\section{Presentation}

A mean age between 60 and 70 years is reported in European studies [10, 11, 59, 60], but is typically a decade younger in studies from the USA [12, 61, 62], which partly reflects the inclusion/noninclusion of patients with HIV.

One of the commonest presenting symptoms in SCCA is rectal bleeding, which can delay diagnosis because bleeding is often attributed to haemorrhoids. The saying "nearly every lesion around the anus is liable to be called 'piles' by the patient and not infrequently by the referring doctor also" remains relevant [63]. Other common presenting symptoms include pain, anal discharge, an unpleasant fishy odour, pruritus ani and ulceration. Once the anal sphincters are involved, patients complain of soiling and then frank faecal incontinence with occasional fistula formation. Often the patient is aware of a lump. Occasionally patients present with enlarged inguinal lymph nodes in the absence of anal symptoms. 


\section{Anatomy and Lymphatic Drainage}

The anal canal is approximately $3-5 \mathrm{~cm}$ in length, depending on the sex of the patient. It starts inferiorly at the anal verge representing the lowermost edge of the sphincter muscles. The anal margin extends from this anal verge and is considered the perianal skin with a $5 \mathrm{~cm}$ radius. The most proximal (i.e. superior) portion of the anal canal drains to perirectal nodes in the mesorectum and nodes along the superior rectal vessels to the inferior mesenteric system, and thereon to the paraaortic nodes, with additional drainage to the internal iliac and obturator nodes.

In tumours arising above the dentate line, drainage is via internal pudendal nodes to the internal iliac system. The upper half of the canal drains mainly by the superior rectal vein to the inferior mesenteric vein, while the lower half drains via the inferior rectal vein. Hence, metastases may occur either to the liver via the portal system or the lung via the systemic circulation, depending on the height of the tumour. Below the dentate line, drainage is to the superficial inguinal nodes, femoral nodes and external iliac nodes. The most frequent sites for nodal metastases are inguinal, femoral and iliac lymph nodes [64]. Clinically palpable (inguinal) lymph nodes are found in 16-25\% of cases $[12,59,65]$. Fewer than $5 \%$ have distant metastases at presentation $[10,59,62]$.

\section{Histopathology}

Histological confirmation is mandatory prior to treatment, as other histological entities are possible in the anal canal. The biopsy specimen should be assessed to document the size of the tumour in terms of the greatest dimension in $\mathrm{mm}$ in all possible planes, and to comment on the resection margins at depth and at the periphery to decide if further treatment is required, particularly for tumours excised at the anal margin, which behave more like skin cancers. However, this may prove impossible if a piecemeal resection has been performed.

In the past, high-grade tumours were expected to be associated with a worse prognosis, but multivariate analysis in the randomised trials has not confirmed this view. Tumours of the anal margin are usually well differentiated and seen in men, but canal tumours are often poorly differentiated and more common in women; however, many view histological grading as subject to considerable interobserver variability and to be of limited prognostic value [66]. There is also heterogeneity observed in larger tumours. Histological subclassifications of basaloid, transitional, spheroidal and cloacogenic cell cancers no longer influence management [13], although some authors retrospectively report that a basaloid histological subtype confers a higher risk of developing metastatic disease [67]. Verrucous carcinoma represents a further variant, which is sometimes described as a giant condyloma or Buschke-Lowenstein tumour.

\section{Prognostic Factors}

Recognised prognostic factors for SCCA are based on standard clinical and biological features, consisting mainly of TNM stage, site of disease, performance status, comorbidities, smoking history and molecular markers such as HPV/p16 status (see below). The clinical factors elicited from the randomised trials are summarised in Table 3. However, even when patients are categorised according to these parameters, there are still considerable differences in behaviour, response and outcome. In future, advances in molecular 
Table 3 Factors implicated in the prognosis of SCCA, as derived from the randomised trials

\begin{tabular}{llllll}
\hline Prognostic factors & $\begin{array}{l}\text { Overall } \\
\text { survival }\end{array}$ & $\begin{array}{l}\text { Disease-free } \\
\text { survival }\end{array}$ & $\begin{array}{l}\text { Locoregional } \\
\text { recurrence }\end{array}$ & $\begin{array}{l}\text { Colostomy } \\
\text { rate }\end{array}$ & $\begin{array}{l}\text { Anal-cancer-associated } \\
\text { death }\end{array}$ \\
\hline Sex & Yes & & Yes & Yes & Yes \\
$\mathrm{N}$ stage & Yes & Yes & & Yes & \\
$\begin{array}{l}\text { T stage/tumor size } \\
(>5 \mathrm{~cm})\end{array}$ & Yes & & Yes & & \\
$\begin{array}{l}\text { Ulceration } \\
\text { Low Hb }\end{array}$ & Yes & & & Yes \\
$\begin{array}{l}\text { Degree of } \\
\text { differentiation }\end{array}$ & Yes & & & & \\
\hline
\end{tabular}

biology and genomic technologies may allow the identification of different genomic and epigenomic patterns developing during tumour progression, and offer greater individualisation in the choice of treatment.

\section{Molecular Biomarkers}

A prognostic biomarker informs regarding the overall outcome for the patient, irrespective of the treatment to be given. In contrast, a predictive biomarker informs regarding the likely effect of a specific therapeutic intervention. Analysis of molecular differences between a large number of tumour specimens could identify such biomarkers, allowing the tailoring of treatment to individual patients and possibly the identification of new therapeutic targets.

\section{Prognostic Biomarkers}

Squamous cell carcinoma antigen (SCCAg) is a serum tumour marker expressed by SCCA which correlates with initial tumour stage and/or nodal status [68]. We have found this marker to be useful in complementing the initial staging and target delineation for radiotherapy, but its clinical utility in diagnosis, prognosis and follow-up remains controversial [69].

In an attempt to distinguish the relative risk of anal exposure to human papillomavirus (HPV) infection, immunodeficiency, and combined antiretroviral therapy in the development of SCCA in HIV-positive men (in particular MSM), a case-control study examined various factors, including the prevalence of HPV E6 antibodies [70]. Current smoking, prior low CD4+ count and antibodies to E6 were significantly associated with SCCA. However, HPV E6, although very specific, is a relatively insensitive biomarker for SCCA.

The most comprehensive review of molecular markers examined different biomarkers belonging to nine functional classes: tumour suppressors, epidermal growth factor receptors (EGFR), apoptosis regulation, proliferation index, angiogenesis, tumour-specific markers (e.g. SCCAg and CEA), Hedgehog signalling, and telomerase [71]. The tumour-suppressor genes p53 and p21 were the only biomarkers demonstrating prognostic value in more than one study. 
Overexpression of p53 is common in anal carcinomas [72, 73] and helps to regulate the cell cycle and apoptosis. Inactivation of p53 leads to dysregulation of key cellular events [73] and may result from either mutations in its gene or sequestration by other cellular proteins, such as the E6 viral oncoprotein of the HPV virus [74]. In an unpublished analysis using samples collected from 240 patients randomised within the UKCCCR ACT I SCCA trial [10], the presence of mutated p53 predicted a poorer cause-specific survival in both arms [75].

\section{Predictive Biomarkers}

In a small study of 30 patients treated with CRT, examination of biomarkers related to chemotherapy and/or radiation resistance suggested on multivariate analysis that Ki67, nuclear factor kappa B, sonic hedgehog, and nuclear Gli-1 are potentially associated with DFS [76].

A recent report explored potential biomarkers with the aim of identifying novel treatment strategies [77]. SCCA specimens were tested via a multiplatform profiling service consisting of gene sequencing, protein expression by immunohistochemistry (IHC) and gene amplification (by CISH or FISH). This study demonstrated frequent expression of resistance-conferring proteins, i.e. multi-drug resistance-associated protein 1 (MRP1); excision repair cross-complementing gene 1 (ERCC1), which confers resistance to platinum-based chemotherapy; and thymidylate synthase (TS), which has a role in fluoropyrimidine resistance [77]. In contrast, the same study identified a number of targetable mutations which occurred with low frequency.

\section{p16INK4A (p16): Prognostic and Predictive}

Cell cycle progression is unchecked via the activation of p16, a cyclin-dependent kinase inhibitor that functions as a checkpoint inhibitor. IHC for p16 has been used as a surrogate for HPV involvement. The analysis of HPV-DNA by either polymerase chain reaction or p16 expression can be used as an independent prognostic marker for both OS and DFS in patients with SCCA [78-80].

p16 expression is associated with greater radiosensitivity in the tumour and possibly with favourable inflammatory responses, although other factors such as smoking modify the better oncological outcomes associated with p16+. However, using p16 expression as a predictive biomarker requires prospective validation in a clinical trial prior to entering routine use (or being used to stratify treatments in future trials).

In contrast, there is increasing recognition that patients with p16-negative SCCA, although uncommon [81], often fail to respond to CRT [79] and generally have worse outcomes following CRT. Relapse-free rates in p16- cases are worse than in p16+ cases $[78,79,82-84]$. Rates of p16 positivity range from $65 \%$ [83] to $93 \%$ [78], so the majority of relapses still occur in p16-positive patients. The more favourable prognosis for p16+ partly reflects intact apoptotic machinery in the cell and low rates of p53 mutation [71, 79], which maintains the response to CRT. The above information suggests that different management strategies/regimens are probably required for tumours which are p16 negative and thereby more difficult to control with standard CRT schedules.

In oropharyngeal cancers, a high circulating neutrophil count is associated with an inferior 
RFS and poor OS, but this effect seems to be limited to patients with p16-positive cancers [85]. In a small retrospective study of 92 patients with SCCA, an elevated neutrophil:lymphocyte ratio (NLR) was associated with worse overall $(p<0.0001)$ and cancer-specific $(p<0.0001)$ survival [86]. Tumour-infiltrating lymphocyte scores can also be used to stratify p16+ cases even further in terms of the risk of relapse [87]. Hence, in $\mathrm{HPV}+/ \mathrm{p} 16+$ SCCA, both the systemic (NLR) and the local inflammatory environment, such as tumour-infiltrating lymphocytes (TILs), may influence clinical outcomes.

\section{Staging and Initial Assessment}

Staging information is useful for determining prognosis but also informs the clinician on the optimal management (i.e. systemic or local) and the choice of treatments. The information is also required by the radiation oncologist to delineate gross tumour volume (GTV) and contour the appropriate nodal and elective volumes. The risk of recurrence may also determine the most appropriate radiotherapy dose and the intensity of follow-up. The unified American Joint Committee on Cancer/ International Union Against Cancer (AJCC/ UICC) staging system incorporates primary tumour size (T), lymph node status (N) and distant metastases $(\mathrm{M})$. The 7 th edition of the AJCC/UICC classification for SCCA is shown in Table 4 [88].

The recommended staging procedures are shown in Table 5 stage by stage. Assessment of each patient with SCCA should specifically include palpation of the groins for the presence of inguinal lymphadenopathyparticularly the superficial inguinal nodes, and those medial and close to the pubis-but radiological assessment with/without fine needle aspirate cytology may also be helpful. Digital rectal examination (DRE) is required to assess the primary tumour and any perirectal/ mesorectal nodal involvement. A vaginal examination is important in women (particularly with anteriorly placed tumours) to determine the site and size of the primary tumour, vaginal/vaginal septal involvement, mucosal involvement and exophytic or ulcerative tumour, or the presence of a fistula. Examination under anaesthesia (EUA) can facilitate accurate clinical staging. Precise tumour measurements and topography need to be documented, as these are often critical for later target volume delineation in radiotherapy treatment planning.

In the UK, magnetic resonance imaging (MRI) of the pelvis is the staging modality of choice, because it provides excellent clarity regarding the primary tumour with multiplanar anatomical detail, and highlights the involvement of surrounding structures [89]. Pelvic MRI also offers more information on nodal involvement, particularly in the mesorectum and inguinal regions, than clinical staging with CT, which is crucial for accurate radiotherapy planning. Distant metastases are assessed with computed tomography (CT) of the thorax and abdomen.

Transrectal ultrasound (TRUS) may be better than MRI in detecting small superficial tumours. TRUS allows a $360^{\circ}$ view of the anal canal and can accurately assess the depth of tumor infiltration and involvement of the sphincter mechanism and fistula tracts. TRUS, however, is poor at assessing lymph node involvement in the mesorectum and pelvis.

Finally, the majority of anal carcinomas are FDG-avid. PET/CT with [18F]fluorodeoxyglucose (FDG-PET/CT) has a high sensitivity in identifying involved lymph nodes, and a high specificity in immunocompetent patients. 
Table 4 Seventh edition of the AJCC/UICC TNM staging for anal canal cancer

Primary tumour $(\mathrm{T})$

$\mathrm{Tx}$

Tis

$\mathrm{T} 1$

$\mathrm{T} 2$

T3

$\mathrm{T} 4$

Regional lymph nodes $(\mathrm{N})$
Primary tumour cannot be assessed

Carcinoma in situ [Bowens disease, high-grade intraepithelial lesion (HSIL), anal intraepithelial neoplasia (AIN) II-III]

Tumour less than $2 \mathrm{~cm}$ in greatest dimension

Tumour between 2 and $5 \mathrm{~cm}$ in greatest dimension

Tumour more than $5 \mathrm{~cm}$ in greatest dimension

Tumour invading adjacent organs [vagina, urethra, bladder, sacrum]

NX Regional nodes cannot be assessed

No No regional lymph node metastasis

N1 Metastasis in perirectal nodes

N2 Metastasis in unilateral internal iliac and/or inguinal nodes

N3 Metastasis in perirectal and/or bilateral internal iliac or inguinal nodes

Distant metastasis $(\mathrm{M})$

M0 No distant metastasis

M1 Distant metastasis

Anatomic stage/prognostic groups

\begin{tabular}{|c|c|c|c|}
\hline 0 & Tis & No & M0 \\
\hline I & $\mathrm{T} 1$ & No & M0 \\
\hline \multirow[t]{2}{*}{ II } & $\mathrm{T} 2$ & No & M0 \\
\hline & T3 & No & M0 \\
\hline \multirow[t]{4}{*}{ IIIA } & $\mathrm{T} 1$ & N1 & M0 \\
\hline & $\mathrm{T} 2$ & N1 & M0 \\
\hline & T3 & N1 & M0 \\
\hline & $\mathrm{T} 4$ & No & M0 \\
\hline \multirow[t]{3}{*}{ IIIB } & $\mathrm{T} 4$ & N1 & M0 \\
\hline & Any $T$ & $\mathrm{~N} 2$ & M0 \\
\hline & Any $T$ & N3 & M0 \\
\hline IV & Any $T$ & Any N & M1 \\
\hline
\end{tabular}

AJCC Cancer Staging Manual, 7th edition (2010)

Hence, FDG-PET/CT can provide information on primary tumour size and lymph node status and can image distant metastases, but lymph nodes

below $8 \mathrm{~mm}$ in size are unlikely to show uptake, even if involved. A study from Mount Vernon suggests that PET/CT can diagnose distant 
Table 5 Recommended investigations/staging policy for SCC of the anus

\begin{tabular}{llllllll}
\hline & T1N0T1N0 & T1N+T1N1 & T2N0T2 & T2N+T2N1 & T3N0T3N0 & T3N+T3N1 & T4T4 \\
& & & N0 & & & & \\
\hline FBC, E+U, LFTs & Yes & Yes & Yes & Yes & Yes & Yes & Yes \\
SCCAg & Yes & Yes & Yes & Yes & Yes & Yes & Yes \\
NR $(1-150 \mathrm{ng} / \mathrm{dl})$ & & & & & & & \\
$\begin{array}{l}\text { CT scan of whole } \\
\text { body }\end{array}$ & Yes & Yes & Yes & Yes & Yes & Yes & Yes \\
$\begin{array}{l}\text { Ultrasound } \\
\text { MRI }\end{array}$ & Sometimes & Sometimes & No & No & No & No & No \\
Diffusion-weighted & Yes & Yes & Yes & Yes & Yes & Yes & Yes \\
MRI & Yes & Yes & Yes & Yes & Yes & Yes \\
PET/CT & No & Yes & Yes & Yes & Yes & Yes & Yes \\
& Unless & & & & & & \\
\hline
\end{tabular}

metastatic disease that CT scan fails to detect, and alters staging in $42 \%$ of patients [90]. PET/CT also has utility in radiation therapy treatment planning as it facilitates the delineation of metabolically active areas, but with poor anatomical definition.

\section{Lymph Nodes}

The risk of inguinal nodal involvement is low if the primary is small [91], but approaches $20 \%$ in cT3 or T4 cancers [92]. It should be borne in mind that $>50 \%$ of involved lymph nodes will measure $<5 \mathrm{~mm}$. Fine needle aspirate cytology (FNAC) of groin nodes can also be helpful.

Sentinel lymph node biopsy (SLNB) can reveal the micrometastatic spread of disease in normal sized lymph nodes, and hence may be more accurate than conventional diagnostic imaging with MRI, CT and PET/CT, but it remains to be validated. A review of five small published series (83 patients) evaluated SLNB in normal-sized inguinal nodes in SCCA [93]. Nodal metastases were found in $7-42 \%$ of cases, and no serious complications were reported. A different review showed more favourable results and identified inguinal metastases in $13 / 63$ patients $(20.6 \%)$ with no false-negative nodes [94]. However, we are not yet in a position to stratify treatment according to macroscopic nodal involvement, microscopic involvement or the presence of a few isolated cells found on SLNB.

Prior to the use of intensity-modulated radiotherapy (IMRT) (which has been shown to reduce acute toxicity), there was a rationale for SLNB to spare formal inguinal irradiation, thereby reducing skin morbidity and damage to the femoral heads. The precision of IMRT means it is possible to contour these areas as organs at risk (OARs) and spare them. The risk of metachronous inguinal node metastasis in patients treated with prophylactic groin radiation appears low (4\%) [61]. The most useful role of SLNB lies in identifying nodes in patients with locoregional recurrence after CRT so as to decide whether radical inguinal dissection is required at the time of salvage 
surgery. There are also concerns that SLNB could delay the start of CRT if healing in the inguinal region is prolonged and prejudice its effectiveness. In one study of SLNB, $24 \%$ of patients had a postoperative complication in the groin [95].

\section{TREATMENT}

\section{Optimising Chemotherapy in Chemoradiation Schedules}

The Radiation Therapy Oncology Group RTOG-8704 trial explored the role of MMC in addition to 5-FU in CRT. The protocol used a median RT dose of $48 \mathrm{~Gy}$ and a potential boost of $9 \mathrm{~Gy}$ for biopsy-confirmed residual disease. The results demonstrated the superiority of $\mathrm{MMC} / 5-\mathrm{FU}$ ( 2 courses of MMC at a dose of $10 \mathrm{mg} / \mathrm{m}^{2}$ ) over 5 -FU alone when combined with radiotherapy [9].

The US Intergroup RTOG 98-11 phase III trial [12] randomly assigned 682 patients (limited to anal canal tumors) to either induction 5-FU and cisplatin for 2 cycles prior to concurrent chemoradiation with 5-FU and cisplatin or the standard arm of concurrent chemoradiation with $\mathrm{MMC} / 5-\mathrm{FU}$. The induction arm failed to improve the primary endpoint of DFS, or locoregional control, distant relapse or overall survival (OS). The risk of a colostomy was significantly higher in the cisplatin arm compared with the mitomycin arm (19\% vs $10 \% ; p=0.02$ ). Haematological toxicity was worse with mitomycin. In a subsequent report of the RTOG98-11, the updated results [4] actually showed an advantage in 5-year DFS for 5-FU/MMC over induction cisplatin and CRT with 5-FU/cisplatin.

In ACT II, using a $2 \times 2$ factorial design [6], patients received 5 -FU $\left(1000 \mathrm{mg} / \mathrm{m}^{2} /\right.$ day on days 1-4, 29-32) and radiotherapy (50.4 Gy in 28 daily fractions), and were randomised to receive a single dose of MMC $\left(12 \mathrm{mg} / \mathrm{m}^{2}\right.$, day 1) or cisplatin $\left(60 \mathrm{mg} / \mathrm{m}^{2}\right.$ on days 1,29$)$. There was a second randomization between two further courses of chemotherapy as consolidation after CRT (5-FU/cisplatin) or no consolidation. In ACT II, the efficacy of adding cisplatin was not significantly different to that of adding MMC to CRT in terms of achieving cCR, reducing tumour relapse or cancer-specific deaths, although haematological toxicity (but not overall toxicity) was higher. Given the superiority of 5-FU/MMC over 5-FU/cisplatin in RTOG98-11 and the nonsignificant excess of second malignancies in ACT II in the groups receiving cisplatin compared to MMC (6 vs 14) or the cisplatin arm in ACT II, 5-FU and MMC $\left(12 \mathrm{mg} / \mathrm{m}^{2}\right.$ day 1 with a maximum recommended dose of $20 \mathrm{mg}$ ) with concomitant RT remain the standard CRT recommended in the UK.

\section{Optimising Radiotherapy}

In the past two decades, trials have refined radiotherapy techniques and proved the efficacy of relatively low total radiation doses. IMRT is considered the current standard. However, the optimal schedules, target volumes and radiation dose remain under debate and continue to be examined in clinical trials.

\section{Field Size}

Relapse can recur either at the primary tumour site, in the regional lymph nodes, or at distant sites. Evidence for the optimal RT dose and fractionation is limited by a lack of data regarding the pattern of failure. No randomised study has published detailed data 
describing the topography and sites of local failure (within, marginal to, or outside of the radiotherapy field). Preliminary data from the ACT II trial suggest the majority of locoregional failures occur in-field [96] and hence can be attributed to an insufficient radiation dose or intrinsic radioresistance rather than inadequate clinical target volumes.

The ACCORD-03 phase III trial [5] compared 45 Gy in 25 daily fractions plus a 15 Gy boost after a gap of 3 weeks with a higher boost dose of 20-25 Gy (i.e. 65-70 Gy total dose), but found no benefit in CFS at doses above $59 \mathrm{~Gy}$, and the optimal boost dose remains undefined.

\section{Radiation Dose}

Higher radiation doses using IMRT and with no extension in the overall treatment time (OTT) are proposed to improve results.

Brachytherapy can also boost a small volume (usually the primary tumour), limiting or sparing the adjacent normal tissues. Delivery of a high-dose "boost" to the primary-tumour area is feasible in selected patients, especially those with more locally advanced disease (T3/ T4) where dose escalation may be of benefit [97]. The technique demands skill and operator experience, and a poor dose distribution risks radionecrosis.

Technological advances such as IMRT, rotational IMRT, image-guided radiotherapy (IGRT) using cone-beam CT (CBCT), and stereotactic techniques allow smaller margins and highly conformal plans, resulting in decreased radiation doses to the organs at risk (OARs) and ensuring a shorter OTT. A prospective phase II study conducted by the Radiation Therapy Oncology Group (RTOG) suggested that a reduction in acute toxicity can be obtained with use of these techniques compared with 2D or 3D techniques [98].
Hence, IMRT is the treatment of choice and is being consistently delivered in the UK according to a newly defined and developing protocol. This is the rationale of the current Plato trial that is funded to start in the UK in 2016.

\section{Optimising Chemotherapy?}

Jean Papillon originally said in 1987 that "The use of chemotherapy during the first days of irradiation is advisable in all cases to reinforce the efficacy of treatment and increase the chance of anal preservation."

\section{Fluoropyrimidines}

Continuous radiosensitisation (i.e. a prolonged venous infusion) during the entire CRT schedule has rarely been investigated in SCCA $[99,100]$. The oral fluoropyrimidine prodrug capecitabine has been examined in the Extra phase I/II trial [101] because its stepwise conversion to 5-FU within the tumour by thymidine phosphorylase theoretically offers a potential therapeutic advantage over intravenous 5-FU alone. Several other investigators have confirmed that capecitabine at a dose of $825 \mathrm{mg} / \mathrm{m}^{2}$ b.i.d. orally is tolerable and appears effective [102-104]. A retrospective comparison of capecitabine and infusional 5-FU suggested capecitabine may even be more effective [105].

\section{MMC}

The central role of MMC in SCCA therapy is well accepted, yet the dose is still not standardised, and optimal doses are unknown. The RTOG-8704 trial used a MMC dose of $10 \mathrm{mg} / \mathrm{m}^{2}$ in weeks 1 and 5 [9]. In contrast, European trials $[6,10,11]$ used a single dose on 
day 1 of MMC at $12 \mathrm{mg} / \mathrm{m}^{2}$ (capped at a $20 \mathrm{mg}$ total dose in the ACT II study). Although MMC has a rapid systemic elimination, it may persist in hypoxic cells as a radiosensitiser for long periods of time. It has a recognised biphasic pattern of haematological toxicity. Hence, it is not clear whether a second dose of MMC on day 29 adds to the efficacy of CRT or not, although it has increased toxicity [9].

\section{Cisplatin}

Various cisplatin doses have been explored in phase II [106, 107] and different retrospective studies of CRT [108-111] between 60 and $80 \mathrm{mg} / \mathrm{m}^{2}$ on days 1 and 29 , without observing an obvious advantage to the higher dose. In contrast to clinical studies in cervical cancer, cisplatin has only been explored in a weekly schedule in a single phase II study [100]. The EORTC 22011-40014 study randomised a control arm of 5-FU and MMC in combination with radiation versus MMC and cisplatin concurrent with radiation using $25 \mathrm{mg} / \mathrm{m}^{2}$ per week, with a total of $175 / \mathrm{mg} / \mathrm{m}^{2}$ [100]. With a median follow-up of 2 years, the 1-year event-free survival was $74.4 \%$ vs $89.2 \%$, respectively, for the novel arm. The schedule was not explored further in a planned phase III design.

A phase II trial at the M.D. Anderson Cancer Center examined the combination of capecitabine and oxaliplatin with radiotherapy [112]. Preliminary results show encouraging response rates of $91-100 \%$ and a CFS of $100 \%$.

\section{Neoadjuvant or Induction Chemotherapy}

The design of the Intergroup trial RTOG-9811 was based on the results of a successful phase II trial [113]. Induction chemotherapy resulted in $8 \mathrm{CR}$ and $21 \mathrm{PR}$ in the 44 evaluable patients.
Only a single patient progressed. Following CRT (which included a mandated 3-week gap) there was a CCR rate of $82 \%$. Overall, 16 patients had persistent $(n=8) \quad$ or subsequent locally recurrent $(n=8)$ disease [113].

These encouraging results led to the development of the RTOG9811 trial, which used the induction regimen as the experimental arm but did not use mitomycin (as an additional potentially non-cross-resistant component)_it was replaced by cisplatinmaking a total of 4 courses of 5-FU/cisplatin [12]. This different novel arm was compared with the standard 5-FU/MMC CRT, but the CALGB study may have raised the acceptance that a gap was not disadvantageous and could be an acceptable treatment strategy.

Induction chemotherapy (ICT) using cisplatin failed to improve OS, DFS, locoregional control and distant relapse when compared to the standard arm. Results after a median follow-up of 2.51 years showed that the 3 - and 5-year DFS rates were $67 \%$ and $61 \%$, respectively, in the MMC arm, versus $61 \%$ and $54 \%$ for the cisplatin arm. The 3- and 5-year OS rates, at $84 \%$ and $75 \%$ for the MMC arm compared to $76 \%$ and $70 \%$, respectively, for the cisplatin arm, were not significantly different $(p=0.1)$ [12]. Interestingly, the results for the CALGB trial parallel those in the RTOG 9811 trial, but in the RTOG 9811 trial, only $26 \%$ of the patients had tumours greater than $5 \mathrm{~cm}$, and $26 \%$ had positive nodes. In contrast, the CALGB trial restricted the eligibility to stage cT3/T4 or lymph node involvement (cN2/N3) [113].

Finally, the ACCORD-03 phase III trial [5] randomised 307 patients in a factorial $2 \times 2$ trial design between 2 cycles of induction chemotherapy (ICT) with 5-FU and cisplatin and secondly a radiation dose escalation. With a mean follow-up of 50 months, the results did 
not show any benefit of ICT compared to standard treatment [5], probably because a 21-day interval was mandated between the main CRT schedule and the boost.

\section{Consolidation/Maintenance \\ Chemotherapy Following \\ Chemoradiation}

The addition of consolidation chemotherapy after CRT is intended to increase efficacy. An early pilot of this strategy in which three cytotoxics were added to radiotherapy in a CRT schedule and also administered as consolidation proved too toxic to consider for a phase III trial [114]. Despite these results, a two-drug maintenance chemotherapy schedule using 5-FU and cisplatin was adopted in the ACT II phase III trial on the basis of this pilot study, i.e. 2 courses of 5 -FU $750 \mathrm{mg} / \mathrm{m}^{2}$ for 4 days and cisplatin $60 \mathrm{mg} / \mathrm{m}^{2}$ on days 71 and 98 (i.e. 11 and 14 weeks from start of treatment) in a second randomization as consolidation. In the ACT II trial there was no significant benefit for consolidation/maintenance chemotherapy [6] in terms of achieving cCR or reducing tumour relapse or cancer-specific deaths compared to the standard arm using MMC/CRT.

\section{The Role of Surgery, Treatment of Small Cancers and Postoperative Adjuvant Treatment}

Smaller lesions ( $<2 \mathrm{~cm}$ in diameter) involving the anal margin can be treated by primary surgery with a local excision provided the surgeon considers that the margins $(>5 \mathrm{~mm}$ ) can be obtained without compromising sphincter function (IVC). This practice is often discouraged because delivery of CRT to residual disease after excision biopsy with positive margins is often delayed and/or compromised by a poorly healing wound cavity. However, local surgical excision is associated with a high risk of close or positive surgical margins, even in small lesions (14/26 positive margins) [115]. Local excision is contraindicated for small tumours in the anal canal.

A few retrospective studies have examined local excision in anal margin tumours, but there are no consistent data regarding appropriate tumour characteristics or a safe excision margin status, or how these features impact on subsequent inguinal node recurrence. Although more extensive and poorly differentiated lesions have a greater risk of being lymph node positive, staging of smaller lesions is important to rule out the presence of positive nodes, as this also is a contraindication for local excision. Some consider that adverse features associated with SCC skin cancers are relevant. These features include tumour diameter $>2 \mathrm{~cm}$, poorly differentiated histology, depth of tumour invasion beyond fat and perineural invasion [116], which account for the majority of poor outcomes and $70 \%$ of patients harbouring regional nodal metastases. However, anogenital lesions were specifically excluded from this analysis.

If a local excision has been performed, simple advancement flaps, with or without faecal diversion, may be used to close the resulting defect, but adjuvant CRT to a dose of 30-36 Gy concurrent chemotherapy using 5 -FU/MMC is often recommended, although many European radiation oncologists tend to use higher doses.

In the case of inadequate margins or R1 resection (found after a resection of "anal tags" or "haemorrhoids"), re-excision is sometimes feasible, but it is difficult for the surgeon to be sure the increased depth of tissue is taken from the correct place. Piecemeal resections render assessment of resection margins in the 
specimen impossible and should not be performed.

However, it is recommended that all patients who have undergone a local resection, irrespective of the resection margin, should be discussed by an appropriate multidisciplinary team (MDT). Nonspecialist surgeons who are less familiar with SCCA sometimes perform local excision with a resulting positive margin, and, in the absence of visible tumor, directing the radiation field may be problematic for the radiation oncologist.

Postoperative CRT is administered if the pathologist is unsure of the completeness of excision, or in cases with positive or narrow margins. Some authors argue that smaller fields can be treated, and that the total dose can be lowered to $30 \mathrm{~Gy}$ for microscopic disease $[117,118]$.

There are still some patients who undergo initial abdominoperineal resection as definitive treatment of their SCCA. This sometimes results from a small poorly differentiated biopsy which is not recognised as SCC histology and treated as a low rectal cancer. Appropriate information such as CDX2 staining should be considered by the pathologist. There are also occasions, if the patient has already received radical radiotherapy to the pelvis, when an abdominoperineal resection is appropriate.

\section{SURVEILLANCE AND SALVAGE SURGERY}

\section{Response Assessment}

There is debate regarding the safest time to define lack of treatment response and persistent local disease. Some have defined persistent disease as the presence of residual carcinoma up to 6 months following the completion of
CRT, and recurrent disease as regrowth of tumour identified $>6$ months from the completion of CRT. Guidelines for SCCA have in the past recommended assessment of response at 6-12 weeks. In early randomised trials and one population study, a single response assessment at 4-8 weeks after the completion of CRT found that $10-60 \%$ of patients fail to respond [9-11]. In ACT I, radical surgery as salvage was intended for patients with $<50 \%$ response at EUA planned for 6 weeks after completion of CRT. The trial results suggested that 29/43 patients with an inadequate clinical response (65\%) actually proceeded to radical surgery [10]. Similarly, in the EORTC trial, radical surgery as salvage was intended for patients with progression or no response [11], and this appears to have been performed in 5 patients in the RT-alone arm but in no patients in the CRT arm. In addition, surgery seems to have been performed in a further 15 patients who achieved either partial or complete remission.

In the RTOG 8704 trial, a biopsy was mandated for patients if residual disease was observed clinically 4-6 weeks after completion of CRT to assess pathological response [9]. A positive biopsy dictated an additional salvage CRT regimen (using $9 \mathrm{~Gy}$ in 5 fractions) concurrently with 5-FU and cisplatin $100 \mathrm{mg} /$ $\mathrm{m}^{2}$, which 25 patients received. If a further repeat biopsy 6 weeks after the salvage CRT was still positive, patients proceeded to APR. The ACCORD-03 trial recommended APR in nonresponders, which was performed in 7 patients [5], so patients with residual tumour proceeded to salvage.

In practice, persistent ulceration can raise suspicion of ongoing nonresponding disease, though definitive histology is usually required before submitting the patient to APR [119]. Positron emission tomography at 1 month has 
also been advocated to assess clinical response [120].

Nowadays, most wait for longer periods to allow assessment of regression. In the ACT II trial, complete clinical response (cCR)-i.e. complete absence of tumour and clinically node negative-was assessed by DRE or imaging at 11 and 18 weeks with a mandated CT at 26 weeks after the start of CRT. At week $11,66 \%$ of patients achieved cCR with MMC and $56 \%$ with cisplatin, compared to $75 \%$ and $76 \%$ at 18 weeks and $83 \%$ and $84 \%$ at 26 weeks, respectively $[6,121]$. So, whilst we would advise careful monitoring of the inguinal region and primary tumour after completion of CRT to facilitate timely surgical salvage for progression, it appears safe to observe a resolving tumour up to 26 weeks following the start of CRT.

\section{Follow-up Surveillance}

Following radical CRT, regression is recognised to be slow, and may take up to 6 months. The guidelines of the American Society of Colon and Rectal Surgeons (ASCRS) suggest that surveillance should be undertaken every 3-6 months for the first 24 months. Our current protocol is that follow-up surveillance should start 12 weeks after the completion of CRT and continue for at least 3-5 years. The patient is reviewed every 3-6 months for a period of 2 years, and subsequently 6- to 12-monthly until 5 years. We perform MRI at 3 and 6 months for low-risk and at 12, 18 and 24 months for high-risk patients. Recommendations for follow-up include digital rectal examination (DRE), anoscopy, inguinal lymph node palpation, and thoracoabdominal CT scan. DRE may fail to detect some locoregional recurrences, and the use and frequency of pelvic MRI surveillance should reflect the perceived risk of local recurrence.

Retrospective studies suggest that $20-25 \%$ of cases develop local recurrence/regrowth within the first 3 years. Patients tend to relapse locoregionally rather than at distant sites, but only $7 \%$ of all locoregional relapses occur beyond 3 years [96]. Hence, there is an argument for performing pelvic MRI surveillance to detect potentially salvageable pelvic failure.

The ideal investigations and the optimal frequency and duration of follow-up after CRT remain a matter of debate. Well-designed, prospective, multi-institutional, randomised studies are needed to define an evidence-based consensus for follow-up. The supportive argument focuses on the early identification of locoregional recurrence amenable to salvage surgery, but it also allows the clinician to manage late effects of treatment on urinary, bowel and sexual function, to provide psychological support, and to ensure that the patient maintains positive changes in diet and lifestyle-in particular smoking cessation. Ongoing regular contact with health care professionals (HCPs) may also improve the detection and management of serious comorbidities.

\section{The Role of Surgery}

\section{Salvage Surgery}

Isolated locoregional relapse from SCCA can be salvaged by a radical abdominoperineal resection (APR), but sometimes it is necessary to consider a posterior or total pelvic exenteration. An APR is extended to encompass adjacent viscera (e.g. the vagina in women) and irradiated soft tissue of the perianal area, perineum, and buttocks, which is a distinct operation from that performed for 
low rectal adenocarcinomas. There is often a need for plastic surgery to reconstruct the perineal defect. Outcomes vary, but a local pelvic disease control rate of approximately $60 \%$ can be achieved if negative surgical margins are achieved with an associated 5-year survival rate of about $40-50 \%[60,122]$. In the largest single series of APR for SCCA, major prognostic factors for survival and recurrence were again $\mathrm{T}$ status and involved margin. This study achieved a 5-year overall survival of $60 \%$ [123]. Other previous studies have identified positive surgical margins, nodal involvement and perineural/lymphovascular invasion as factors associated with survival [124]. In a small study from Swansea, 11/96 (12\%) required salvage surgery following CRT, five of whom were stage $\mathrm{T} 4$ at presentation. Six patients had failed to respond to CRT, and five presented with recurrence at a median of 10 (10-36) months [125].

Since most locoregional recurrence occurs within the first 3 years following CRT [96], some surgical groups have adopted a proactive approach with sequential surveillance CT or pelvic MRI to detect early relapse, taking the view that there may be a limited window of opportunity to resect a local disease relapse. In the Manchester series of 254 patients treated with curative intent, 73/99 relapses (74\%) underwent salvage APR [60]. The corresponding rate in the contemporaneous UKCCCR ACT I trial was only 56\% [10].

\section{Late Effects}

The majority of patients with SCCA are cured by CRT, and surgery can salvage at least $50 \%$ of local relapses. Hence, if patients survive long term, it is even more important to minimise late effects, which are infrequently reported and poorly recorded in phase III trials. There is a wide spectrum of effects, from minor persistent symptoms to life-threatening complications, but there is still no widely accepted classification for describing late morbidity of radiation. The WHO and RTOG/ECOG systems, used in the EORTC, ACT I and RTOG-8704 trials, were not specifically designed to capture radiation-induced morbidity.

The ACT I trial defined any toxicity occurring or persisting more than 6 months after completing initial radiotherapy as late morbidity. Toxicity was not scored or quantified [3] but simply described, and was more common in the subgroup who received boost by implant (14\%) compared with an EBRT boost $(6 \% ; p=0.003)$, although post-treatment biopsies for suspicion of residual disease might have contributed in some to nonhealing and ulceration. The ACT II trial collected regular descriptive reports of the presence or not of a range of late effects (bowel, urinary and sexual) which were considered by the investigator to be severe but were not formally graded according to the RTOG scale. However, many patients have severe G3/G4 late effects [126], and up to $20 \%$ historically required a colostomy for these adverse late effects alone [127].

Long-term colostomy rates vary from $15 \%$ to $36 \%$ in the randomised trials $[10,11]$ and population studies [59], of which approximately $10 \%$ are fashioned initially for symptom control. Most of these are never reversed. In addition, $10-15 \%$ of colostomies are required to deal with the consequences of treatment $[3,12]$. In the RTOG-9811 trial, the rate of severe long-term toxic effects was similar in both arms, $11 \%$ vs. $10 \%$, but only $5 \%$ required a colostomy for treatment-related problems.

Hence, nurse-led clinics promoting survivorship in patients who have received pelvic radiotherapy are gaining support $[128,129]$. These identify late effects, enabling 
therapeutic interventions and counselling to reduce the psychosocial and physical impacts of such symptoms. There are also reports detailing the effectiveness of pelvic floor exercises and/or biofeedback training in patients who experience faecal urgency and incontinence.

\section{Quality of Life}

Effects of treatment on long-term quality of life (QOL) in patients with SCCA based on data within the published randomised trials have not been published, partly due to the absence of an available validated questionnaire specific to SCCA at the time of trial design. Preliminary data from ACT I [130] were presented in an abstract only. In the ACCORD-03 study, an early assessment at 2 months after completion of CRT did not show that NACT and high-dose radiotherapy, either alone or in combination, had a negative impact on quality of life [131]. In fact, QOL appeared to be better than the QOL defined at entry prior to CRT.

Retrospective analysis of long-term QOL suggests there is a high rate of faecal incontinence $[7,132]$ sexual problems in both males and females as well as financial difficulties, even 5 years later. However, some studies seem to demonstrate that QOL is satisfactory to patients despite an objective impairment of sphincter function [133, 134]. There has been a recent systematic review on this topic [135]. Currently, a specific EORTC anal cancer module is being developed to replace several other modules that are frequently used-EORTC QLQ-C30 and-CR29 (colorectal cancer), EORTC QLQ-PRT23 (for radiation proctitis) and EORTC QLQ-PR25 (for prostate cancer)-to include all QOL issues relevant and specific to anal cancer, and with a focus on pelvic toxicities and stoma placement.

\section{TREATMENT OF METASTATIC DISEASE}

Carcinoma of the anus rarely spreads outside the pelvis unless the primary tumour is unresponsive to chemoradiation or local failure is observed. Distant disease at presentation is reported in less than $5 \%$ of cases, and usually involves para-aortic nodes, lung, liver or bone.

Although single-agent carboplatin has been examined, the combination of 5-FU and cisplatin remains the most commonly used palliative regimen, and it is the only regimen recommended in the NCCN guidelines [14]. Response rates of $20-60 \%$ are reported when this regimen is used as the first-line therapy, but such rates are rarely sustained. Few reports have included more than a handful of patients. There is currently an international randomised phase II trial comparing the standard of 5-FU/cisplatin against carboplatin/taxol in progress under the aegis of the IRCF (Interract NCT). Clinical decisions such as whether to continue therapy until resistance or toxicity is reached as opposed to stopping treatment after a defined number of chemotherapy cycles in metastatic SCCA remain unanswered. Randomised trials incorporating EGFR inhibitors might be a useful consideration, especially in those with wild-type KRAS tumours.

\section{NEW DIRECTIONS}

\section{Intensity-Modulated Radiotherapy}

Technical advances in radiation oncology such as IMRT allow better precision with adequate doses of radiotherapy to the tumour while sparing sensitive normal surrounding structures such as perineal skin, the external 
genitalia, the bony confines of the pelvis (sacrum and pubis), the femoral head and neck, the bladder and the small bowel. IMRT also offers the potential for dose escalation of the radiotherapy. IMRT appears most useful in tumour sites with a marked dose-response curve (such as prostate cancer and head and neck cancer) or that are close to critical organs.

The ACT II trial used low doses to treat the nodes electively in the first phase of treatment (30.6 Gy in 17 daily fractions), which successfully prevented disease at these sites [6]. There is further retrospective support for the efficacy of a low-dose (36 Gy) elective nodal irradiation [136]. The differential doses required for elective nodal irradiation and the gross primary/nodal tumour favour the use of IMRT. The shapes of the lymph node targets in the pelvis are predominantly concave, and it is difficult to spare normal tissue using 3D-CRT techniques. With IMRT or rotational IMRT using highly modulated dose fluence from multiple directions, we can limit the high-dose volume outside the treatment target, reducing the dose to OARs and thereby modifying acute and late toxicity.

Sparing the anal canal is difficult, and the maximal dose to the sphincters may predict the risk of complications. There is limited evidence regarding long-term function, but the maximum dose to the anal canal has been recommended by some to be only 55 Gy [137].

A multicentre study of IMRT [138] reduced acute grade 3 toxicity and still maintained good LC. Further data from this study showed that the volume of bowel receiving $30 \mathrm{~Gy} V(30)$ correlated with acute gastrointestinal (GI) toxicity in chemo IMRT-treated SCCA patients. Similarly, IMRT treated elective pelvic regions and inguinal nodes (to $45 \mathrm{~Gy}$ ) but reduced the volume of pelvic bone marrow receiving 15 and 20 Gy (PBM-V15 and PBM-V20), which appears to affect the absolute nadir neutrophil count (ANC) [139]. This sparing of normal tissues may allow improved compliance and maintains a short OTT. Late morbidity is likely to be reduced, albeit at the price of more second malignancies because of the wide-field low doses.

\section{Biological Agents}

\section{EGFR Inhibition}

EGFR is overexpressed in up to $90 \%$ of SCCAs [140-142], and EGFR, K-RAS or BRAF mutations are rarely identified [141, 143-146], although one study showed that PIK3CA was mutated in $22 \%$ of cases [145]. Pre-clinical studies suggest that inhibiting EGFR signalling slows cell proliferation in vitro and in vivo and promotes additive effects with radiotherapy [147]. EGFR contributes to tumour development and progression through autocrine stimulation of cell proliferation. In addition, radiation itself induces EGFR activation, which contributes-at least in part-to the mechanism of accelerated proliferation, and can be expected to increase the capacity for tumour DNA damage repair. Overexpression of epidermal growth factor receptor (EGFR) has been linked to radioresistance [148, 149].

A landmark phase III study in patients with locally advanced squamous cell head and neck cancer [150] showed that cetuximab (a recombinant, chimeric monoclonal antibody directed against the epidermal growth factor receptor) in combination with radical radiotherapy significantly improved overall survival compared to radiation alone. Hence, there may be a therapeutic role for agents causing EGFR inhibition in SCCA either as a single agent with radiation or in combination with standard CRT. 
In SCCA, several small studies have evaluated the combination of 5-FU, cisplatin and cetuximab with radiation. In a Brazilian study [151], 23 patients were enrolled, butdespite a response rate of $95 \%$-the study was closed early due to toxicity, including $6(26 \%)$ episodes of thrombosis and embolism, 12 (52\%) cases of severe grade 3-4 radiation dermatitis and 10 (44\%) cases of grade 3-4 diarrhoea.

The ACCORD 16 phase trial also evaluated cetuximab in combination with CRT using 5 -FU, cisplatin and $45 \mathrm{~Gy}$ of $\mathrm{RT}$, but it too closed early because the authors concluded that the toxicity was unacceptable [152], with serious adverse events seen in 14 out of 16 patients (i.e. grade $3 / 4$ acute toxic effects in $88 \%$ of patients), although there were no toxic deaths.

Two other small phase II studies in the USA (ECOG 3205 for immunocompetent patients; AMC045 for HIV-positive patients) showed more reasonable clinical outcomes for patients treated with the combination of cetuximab with 5-FU and cisplatin concurrently with radiation. These studies included 45 and 28 patients, respectively, and reported 2-year OS rates of $89 \%$ and $93 \%$ [153].

The ECOG 3205 phase II trial had two cohorts: cohort A included induction chemotherapy with cisplatin and 5-fluorouracil followed by CRT with cetuximab, cisplatin, and 5-fluorouracil to a total radiation dose of $54 \mathrm{~Gy}$. Arm B had the same CRT doses and schedule as arm A but without the induction chemotherapy. Arm A closed after the accrual of 28 patients and the induction arm was discontinued. For the 28 subjects in arm A, preliminary results showed that the colostomy rate was $14 \%$, the 2 -year PFS was $92 \%$, and the 2-year OS was $93 \%$. The primary endpoint of failure at 3 years was not reached. Results for arm B are not yet available.
The AIDS Malignancy Consortium treated HIV-positive patients in a phase II trial (AMC045) using CRT with cetuximab, cisplatin, and 5-fluorouracil, similar to ECOG 3205 . The 2 -year local/regional failure rate was 7\%, 2-year OS 89\%, and 2-year colostomy rate $7 \%$. It is unclear why neither ECOG 3205 nor AMC045 reported the unwelcome and unusual toxicity seen in ACCORD16 and the phase I study [151, 152], although it may reflect differences in the radiation dose, the field size or the patient population.

Finally, a recent phase I study employed IMRT and combined cetuximab with 5-FU/ MMC-based CRT using a simultaneous integrated boost (SIB) administering 57.5/54.0/ 48.6 Gy in 27 fractions to primary tumor/lymph node metastases/adjuvant lymph node regions, respectively [154]. Toxicity was acceptable, and 3 months following completion of CRT, 10/11 patients (91\%) achieved local complete remission (CR). The MTDs for the agents combined with cetuximab were determined as 5 -FU $800 \mathrm{mg} / \mathrm{m}^{2}$ on RT days $1-4$ and 29-32 and MMC $8 \mathrm{mg} / \mathrm{m}^{2}$ on days 1 and 29 . Hence, there is insufficient evidence to recommend the use of cetuximab in concurrent CRT in SCCA (see Table 6).

Two further phase II studies (NCT01843452 and NCT01285778) are currently evaluating the benefit of the addition of panitumumab to CRT with capecitabine and mitomycin C. The Vital trial (NCT01285778) has finished recruiting patients.

\section{PI3K/AKT/mTOR Pathway}

The phosphatidylinositol 3-kinase pathway offers a further potential therapeutic target for SCCA because this pathway appears associated with clinical radioresistance in HPV-related SCCHN [148]. (PI3K)/AKT is hyperactivated in 
Table 6 Preliminary and full results of phase I/phase II studies integrating cetuximab into CRT regimens

\begin{tabular}{|c|c|c|c|c|c|}
\hline Trial & No of patients & IMRT & Regimen & Toxicity & Efficacy \\
\hline Olivatto et al. [151] & $\begin{array}{l}21 \text { (stopped because } \\
\text { of DLT) }\end{array}$ & No & $\begin{array}{l}\text { 5-FU/CP } \\
\quad+\mathrm{RT}+\text { cetuximab }\end{array}$ & High $^{a}$ & OK \\
\hline $\begin{array}{l}\text { ACCORD 16, Deutsch } \\
\text { et al. [152] }\end{array}$ & $\begin{array}{l}16 \text { (stopped because } \\
\text { of DLT) }\end{array}$ & No & $\begin{array}{l}\text { 5-FU/CP } \\
\quad+\mathrm{RT}+\text { cetuximab }\end{array}$ & High $^{a}$ & Low [169] \\
\hline $\begin{array}{l}\text { ECOG 3205, Garg et al. } \\
{[153]}\end{array}$ & 28 & Some & $\begin{array}{l}\text { 5-FU/CP } \\
\quad+\mathrm{RT}+\text { cetuximab }\end{array}$ & Low $^{a}$ & $93 \%$ OS at 2 years \\
\hline Leon et al. [154] & 13 & Yes & $\begin{array}{l}\text { 5-FU/MMC } \\
\quad+\mathrm{RT}+\text { cetuximab }\end{array}$ & Low $^{a}$ & $73 \% \mathrm{CR}$ at 3 months \\
\hline
\end{tabular}

${ }^{a}$ Our subjective interpretation of the toxicity in terms of being able to deliver the schedule within a randomised trial

many squamous cell cancers, particularly HPV-related head and neck cancers. Mutations in PIK3CA, Akt1 and FBXW7 are frequent, along with PTEN loss, suggesting a potential for targeting the PI3K pathway. Mutations in PIK3CA were reported in $13 / 84$ patients with SCCA (16\%) and KRAS mutations in 4/84 (5\%), respectively [142], and a study of 128 patients with SCCA showed that $66 \%$ had cellular accumulation of phosphorylated AKT. There was a significant correlation between HPV infection and activated AKT [155] and high frequency of copy number gain at PIK3CA $(47 \%)$. There are now some agents such as the Akt inhibitor afuresertib in development that are able to target this signalling pathway and could be explored as combinations with chemotherapy and radiotherapy.

\section{Immunotherapy}

The importance of functional immune surveillance in controlling cancer is well recognised. Studies in SCCA show a correlation between tumor-infiltrating lymphocytes (TILs) in cancer tissue and a favourable prognosis. In particular, the presence of $\mathrm{CD} 8+\mathrm{T}$ cells and the ratio of
CD8+ effector $\mathrm{T}$ cells to FoxP3+ regulatory $\mathrm{T}$ cells seem to be correlated with improved prognosis and long-term survival in many solid tumors. SCCA is no exception.

Tumours upregulate inhibitory molecules such as programmed death receptor-1 (PD-1) and its ligands PD-L1 and PD-L2, which suppress the host antitumour immune response and antagonise any immunogenic effects HPV or CRT can raise. The normal function of PD-1, expressed on the cell surface of activated $\mathrm{T}$ cells, is to downmodulate unwanted or excessive immune responses, including autoimmune reactions. If the PD-1 ligand from the cancer cells binds to its receptors on activated $\mathrm{T}$ cells, then the $\mathrm{T}$ cell is unable to recognise or produce any immunological effects on cancer cells or indeed any antigens [156]. This activation facilitates cancer progression. Many cancer cells, including SCCA, express the PD-1 ligand. A recent small study reported the presence or absence of PD-L1 expression in 41 patients with SCCA. PD-L1 expression was seen in $62 \%$ of cases with late/unknown-stage disease and 33\% of cases with early-stage disease [157].

Interestingly, in non-small-cell lung cancer, current smokers are significantly more likely to 
express the PD-1 receptor than nonsmokers. Immunotherapy drugs which block the binding of the PD-1 ligand to its receptor, allow activated T cells to recognise and infiltrate cancer cells. The precise threshold for meaningful PD-L1 positivity with immunohistochemistry (IHC) assays to predict response to such agents remains controversial. Pembrolizumab is a humanised monoclonal antibody against PD-1 which blocks PD-1 receptors binding the cancer cells PD-L1. The KEYNOTE trials of pembrolizumab used a high breakpoint (50\%) for PD-L1 expression. Proof of principle of activity was achieved in a study presented at ESMO 2015 which included 25 heavily pretreated patients with PD-L1-positive advanced SCCA; in that study, pembrolizumab demonstrated a manageable safety profile with an overall response rate of 5/25 (20\%) and stable disease in a further 10 patients (40\%) [158]. Additionally, there are now many studies suggesting synergistic effects on LC and abscopal effects on distant tumour control when radiation therapy is combined with immunotherapy $[159,160]$. This has led to the hypothesis that combining radiation with checkpoint blockade immunotherapy will increase radiosensitisation, improve local tumour control and prevent the development of overt metastatic disease by reactivating antitumour $\mathrm{T}$ cells which have become tolerant.

As mentioned above, HPV plays an important role in the development and progression of SCCA, the majority being associated with HPV-16 and HPV-18. Some have suggested that the favourable outcomes from HPV + tumours compared to HPV - tumours are because HPV antigens may elicit a host immune response directed against the cancer cells. T-cell migration into tumour masses may be critical to the process of immunologically induced tumour regression. Reports suggesting improved outcomes in SCCA tumours with massive TILs [161] support this hypothesis. If a clear biological relevance of the TIL response can be shown in SCCA, this would support trials of immunotherapy (targeting immune checkpoints via anti CTLA4/PD1/PDL1 agents) in this tumour type, either in the metastatic setting or potentially combined with chemoradiotherapy, either in the concurrent or (neo)adjuvant setting [162].

An alternative strategy is the use of autologous TILs targeting HPV. White blood cells are harvested from the patient's tumour, grown in the laboratory in large numbers, and then injected back into the patient. Promising results have been observed in other SCCs such as cervical cancer and head and neck cancer. There is a currently open phase II trial (NCT01585428) that is studying autologous TILs and high-dose interleukin-2 for HPV-associated cancers, including SCCA following a lymphodepletion.

SCCA cells infected by HPV also have the tumour-associated antigen HPV E7. The viral gene products E6 and E7 are responsible for the oncogenic potential by inhibiting normal cell cycle checkpoints and inducing cell division, which can be targeted immunologically. Normal antiviral immune defence systems do not come into play because of the HPV16-E6 and E7 oncoproteins [163]. E6 lowers the levels of E-cadherin on the surface of keratinocytes, which in turn (because of modified adhesion properties) aids the survival of the virus by limiting the presentation of viral antigens to the immune system [164]. A further phase I/II study (NCT02280811) uses T-cell receptor immunotherapy targeting HPV-16 E6. This study is similar to the above except that the cells are genetically modified with a retrovirus to attack tumour cells.

ADXS11-001 is a live attenuated Listeria monocytogenes $(\mathrm{Lm})$ bioengineered to secrete a HPV-16 E7 fusion protein targeting 
HPV-transformed cells. This vaccine aims to elicit an immune response against human papillomavirus (HPV) oncoprotein E7 [165]. In preclinical studies, ADXS-HPV generates T-cells directed against a cancer antigen neutralise Tregs and myeloid-derived suppressor cells (MDSCs), which protect the tumour microenvironment from immunologic recognition and contribute to tumour growth. ADXS11-001 is currently being evaluated for treatment of cervical cancer and SCCA in phase I/II clinical trials. A current phase II trial in SCCA is evaluating ADXS11-001 in combination with concurrent 5-FU, mitomycin and IMRT (NCT01671488). ADXS11-001 causes antigen-presenting cells to be stimulated, and thereby facilitates the attachment of immune cells to SCCA cells expressing HPV E7. Activity has already been demonstrated in recurrent/refractory SCC of the cervix [166, 167], where a phase III trial is underway.

Finally, CHK1 is a multifunctional kinase crucial for checkpoint control, DNA repair, cell cycle replication, and proliferation. By inhibiting CHK1, tumour DNA is damaged and unable to pass through mitosis. The $\mathrm{CHK} 1 / 2$ inhibitor (LY2606368) is being investigated as a single agent in patients with metastatic SCCA [168].

\section{CONCLUSION}

Future prevention of SCCA is feasible, but is likely to rely on effective vaccination and screening measures. In established SCCA, clinical staging using the tumour/node/ metastasis (TNM) categorisation does not predict response to treatment and outcomes for the individual with confidence. We have a standard regimen of 5-FU/MMC CRT for all patients. Yet, early cT1 tumours with a locoregional control of $>90 \%$ are probably overtreated with current regimens, while cT3/ T4 lesions have a 3-year DFS of only 35-68\% and thus might benefit from more intensive treatment and a proactive approach to surgical salvage. Some patients experience only limited benefit from CRT and are still left with significant late morbidity. After decades of research, we have not found robust markers for radioresponsiveness that can be applied in the clinic. The response to CRT is heterogeneous and may reflect the tumour environment and the immunological capacity more than innate radiosensitivity.

Current more-sophisticated risk assessment techniques (using p16, SCCAg, PET/CT, TSIL, PD-1 expression) may allow us to stratify SCCA more accurately and help to tailor the intensity of treatment to the individual. The increased precision with IMRT can spare critical normal tissues, may reduce acute toxicity and/or allow dose escalation to be performed safely. Integration of novel biological therapies with conventional chemotherapies so far have not improved outcomes. The most hopeful addition to treatment lies with immune modulators and the checkpoint inhibitors such as PD-1 inhibitors, which have shown spectacular early promise.

However, it will be important to ensure these novel treatments do not impact adversely on acute toxicity and late function, which is likely to have a knock-on effect on colostomy-free survival. Both the effectiveness of treatment and the risk of developing severe toxicity with radical CRT depend on the genetic background of the patient, the past and present lifestyle, the already acquired morbidity as well as the size and stage of the tumour, the intensity of chemotherapy and the total dose of radiotherapy. Understanding the molecular and immunological characteristics of both the tumour and the whole patient are 
therefore going to be important in attempts to identify predictive biomarkers and individualise treatment.

\section{ACKNOWLEDGMENTS}

No funding or sponsorship was received for this study or the publication of this article. All named authors meet the International Committee of Medical Journal Editors (ICMJE) criteria for authorship for this manuscript, take responsibility for the integrity of the work as a whole, and have given final approval for the version to be published.

Disclosures. Rob Glynne-Jones has received honoraria for lectures and advisory boards and has been supported in attending international meetings by Merck, Pfizer, Sanofi-Aventis and Roche. He has also received unrestricted grants for research from Merck Serono, Sanofi-Aventis and Roche. Marcia Hall has received honoraria for attending advisory boards for Merck, AstraZeneca, Roche and GlaxoSmithKline. Waqar Saleem, Suzy Mawdsley and Mark Harrison declared no conflict of interest.

Compliance with Ethics Guidelines. This article is based on previously conducted studies and does not involve any new studies of human or animal subjects performed by any of the authors.

Open Access. This article is distributed under the terms of the Creative Commons Attribution-NonCommercial 4.0 International License (http://creativecommons.org/licenses/ by-nc/4.0/), which permits any noncommercial use, distribution, and reproduction in any medium, provided you give appropriate credit to the original author(s) and the source, provide a link to the Creative Commons license, and indicate if changes were made.

\section{REFERENCES}

1. Siegel R, Ward E, Brawley O, Jemal A. Cancer statistics, 2011: the impact of eliminating socioeconomic and racial disparities on premature cancer deaths. CA Cancer J Clin. 2011;61(4):212-36.

2. Wilkinson JR, Morris EJ, Downing A, Finan PJ, Aravani A, Thomas JD, Sebag-Montefiore D. The rising incidence of anal cancer in England 1990-2010: a population-based study. Colorectal Dis. 2014;16(7):O234-9.

3. Northover J, Glynne-Jones R, Sebag-Montefiore D, James R, Meadows H, Wan S, et al. Chemoradiation for the treatment of epidermoid anal cancer: 13-year follow-up of the first randomised UKCCCR Anal Cancer Trial (ACT I). $\mathrm{Br} J$ Cancer. 2010;102(7):1123-8.

4. Gunderson LL, Winter KA, Ajani JA, Pedersen JE, Moughan J, Benson AB 3rd, et al. Long-term update of U.S. GI Intergroup RTOG 98-11 phase III trial for anal carcinoma: survival, relapse and colostomy failure with concurrent chemoradiation involving fluorouracil/mitomycin versus fluoruracil/cisplatin. J Clin Oncol. 2012;30:4344-51.

5. Peiffert D, Tournier-Rangeard L, Gerald JP, Lemanski C, Francois E, Giovannini $M$, et al. Induction chemotherapy and dose intensification of the radiation boost in locally advanced anal canal carcinoma: final analysis of the randomized UNICANCER ACCORD 03 trial. J Clin Oncol. 2012;30:1941-4.

6. James RD, Glynne-Jones R, Meadows $H$, Cunningham D, Myint AS, Saunders MP, et al. Mitomycin or cisplatin chemoradiation with or without maintenance chemotherapy for treatment of squamous-cell carcinoma of the anus (ACT II): a randomised, phase 3 , open-label, $2 \times 2$ factorial trial. Lancet Oncol. 2013;14:516-24.

7. Bentzen AG, Guren MG, Vonen B, Wanderås EH, Frykholm G, Wilsgaard T, et al. Faecal incontinence after chemoradiotherapy in anal cancer survivors: long-term results of a national cohort. Radiother Oncol. 2013;108(1):55-60.

8. Gunderson LL, Moughan J, Ajani JA, Pedersen JE, Winter KA, Benson AB 3rd, Thomas CR Jr, Mayer RJ, Haddock MG, Rich TA, Willett CG. Anal carcinoma: 
impact of TN category of disease on survival, disease relapse, and colostomy failure in US Gastrointestinal Intergroup RTOG 98-11 phase 3 trial. Int J Radiat Oncol Biol Phys. 2013;87(4):638-45.

9. Flam M, John M, Pajak TF, Petrelli N, Myerson R, Doggett S, Quivey J, Rotman M, Kerman H, Coia L, Murray K. Role of mitomycin in combination with fluorouracil and radiotherapy, and of salvage chemoradiation in the definitive nonsurgical treatment of epidermoid carcinoma of the anal canal: results of a phase III randomized intergroup study. J Clin Oncol. 1996;14(9):2527-39.

10. UKCCCR Anal Cancer Working Party. Epidermoid anal cancer: results from the UKCCCR randomised trial of radiotherapy alone versus radiotherapy, 5-fluorouracil and mitomycin. Lancet. 1996;348:1049-54.

11. Bartelink H, Roelofsen F, Eschwege F, Rougier P, Bosset JF, Gonzalez DG, Peiffert D, van Glabbeke M, Pierart M. Concomitant radiotherapy and chemotherapy is superior to radiotherapy alone in the treatment of locally advanced anal cancer: results of a phase III randomized trial of the European Organization for Research and Treatment of Cancer Radiotherapy and Gastrointestinal Cooperative Groups. J Clin Oncol. 1997;15(5):2040-9.

12. Ajani JA, Winter KA, Gunderson LL, Pedersen J, Benson AB 3rd, Thomas CR Jr, Mayer RJ, Haddock MG, Rich TA, Willett C. Fluorouracil, mitomycin, and radiotherapy vs fluorouracil, cisplatin, and radiotherapy for carcinoma of the anal canal: a randomized controlled trial. JAMA. 2008;299(16):1914-21.

13. Glynne-Jones R, Nilsson PJ, Aschele C, Goh V, Peiffert D, Cervantes A, Arnold D. Anal cancer: ESMO-ESSO-ESTRO clinical practice guldelines for diagnosis treatment and follow up. Ann Oncol. 2014;25(Suppl 3):iii10-20.

14. NCCN. NCCN Clinical Practice Guidelines in Oncology: anal carcinoma, version 1, 2016. https://www.nccn.org/professionals/physician_gls/ f_guidelines.asp.

15. Boman BM, Moertel CG, O'Connell MJ, Scott M, Weiland LH, Beart RW, Gunderson LL, Spencer RJ. Carcinoma of the anal canal. A clinical and pathologic study of 188 cases. Cancer. 1984;54(1):114-25.

16. Bilimoria $\mathrm{KY}$, Bentrem DJ, Rock CE, et al. Outcomes and prognostic factors for squamous-cell carcinoma of the anal canal: analysis of patients from the National Cancer Data Base. Dis Colon Rectum. 2009;52(4):624-31.
17. Palmer JG, Scholefield JH, Coates PJ, et al. Anal cancer and human papillomaviruses. Dis Colon Rectum. 1989;32:1016-22.

18. De Vuyst H, Clifford GM, Nascimento MC, Madeleine MM, Franceschi S. Prevalence and type distribution of human papillomavirus in carcinoma and intraepithelial neoplasia of the vulva, vagina and anus: a meta-analysis. Int $\mathrm{J}$ Cancer. 2009;124(7):1626-36.

19. Williams GR, Lu QL, Love SB, Talbot IC, Northover JM. Properties of HPV-positive and HPV-negative anal carcinomas. J Pathol. 1996;180(4):378-82.

20. Grulich AE, van Leeuwen MT, Falster MO, et al. Incidence of cancers in people with HIV/AIDS compared with immunosuppressed transplant recipients: a meta-analysis. Lancet. 2007;370(9581):59-67.

21. Brewster DH, Bhatti LA. Increasing incidence of squamous cell carcinoma of the anus in Scotland, 1975-2002. Br J Cancer. 2006;95(1):87-90.

22. Nordenvall C, Nilsson PJ, Ye W, Nyren O. Smoking, snus use and risk of right- and left-sided colon, rectal and anal cancer: a 37-year follow-up study. Int J Cancer. 2011;128(1):157-65.

23. Tseng HF, Morgenstern H, Mack TM, Peters RK. Risk factors for anal cancer: results of a population-based case-control study. Cancer Causes Control. 2003;14(9):837-46.

24. Linam JM, Chand RR, Broudy VC, et al. Evaluation of the impact of HIV serostatus, tobacco smoking and CD4 counts on epidermoid anal cancer survival. Int J STD AIDS. 2012;23(2):77-82.

25. Slesser AA, Bhangu A, Bower M, Goldin R, Tekkis PP. A systematic review of anal squamous cell carcinoma in inflammatory Crohn's disease compared to the general population implying a more aggressive bowel disease. Surg Oncol. $2013 ; 22(4): 230-7$.

26. Frisch M, Johansen C. Anal carcinoma in inflammatory bowel disease. $\mathrm{Br} \mathrm{J}$ Cancer. 2000;83(1):89-90.

27. Frisch M, Olsen JH, Melbye M. Malignancies that occur before and after anal cancer: clues to their etiology. Am J Epidemiol. 1994;140(1):12-9.

28. Silverberg MJ, Lau B, Justice AC, Engels E, Gill MJ, Goedert JJ, et al. Risk of anal cancer in HIV-infected and HIV-uninfected individuals in North America. Clin Infect Dis. 2012;54(7):1026-34.

29. Bjorge T, Engeland A, Luostarinen T, Mork J, Gislefoss RE, Jellum E, Koskela P, Lehtinen M, 
Pukkala E, Thoresen SO, Dillner J. Human papillomavirus infection as a risk factor for anal and perianal skin cancer in a prospective study. Br J Cancer. 2002;87(1):61-4.

30. Palefsky JM, Holly EA, Ralston ML, Jay N. Prevalence and risk factors for human papillomavirus infection of the anal canal in human immunodeficiency virus (HIV)-positive and HIV-negative homosexual men. J Infect Dis. 1998;177(2):361-7.

31. Baseman JG, Koutsky LA. The epidemiology of human papillomavirus infections. J Clin Virol. 2005;32(suppl 1):S16-24.

32. Shvetsov YB, Hernandez BY, McDuffie K, et al. Duration and clearance of anal human papillomavirus (HPV) infection among women: the Hawaii HPV. Clin Infect Dis. 2009;48(5):536-46.

33. zur Hausen H. Papillomaviruses in the causation of human cancers-a brief historical account. Virology. 2009;384(2):260-5.

34. Mammas IN, Sourvinos G, Giannoudis A, Spandidos DA. Human papilloma virus (HPV) and host cellular interactions. Pathol Oncol Res. 2008;14(4):345-54.

35. Licitra L, Perrone F, Bossi P, Suardi S, Mariani L, Artusi $\mathrm{R}$, et al. High-risk human papillomavirus affects prognosis in patients with surgically treated oropharyngeal squamous cell carcinoma. J Clin Oncol. 2006;24(36):5630-6.

36. Lemarchand $\mathrm{N}$, Tanne $\mathrm{F}$, Aubert $\mathrm{M}$, et al. Is routine pathologic evaluation of hemorrhoidectomy specimens necessary? Gastroenterol Clin Biol. 2004;28(8-9):659-61.

37. Kreuter A, Brockmeyer NH, Hochdorfer B, et al. Clinical spectrum and virologic characteristics of anal intraepithelial neoplasia in HIV infection. J Am Acad Dermatol. 2005;52(4):603-8.

38. Scholefield JH, Castle MT, Watson NF. Malignant transformation of high-grade anal intraepithelial neoplasia. Br J Surg. 2005;92(9):1133-6.

39. Watson AJ, Smith BB, Whitehead MR, Sykes PH, Frizelle FA. Malignant progression of anal intra-epithelial neoplasia. ANZ J Surg. 2006;76(8):715-7.

40. Zbar AP, Fenger C, Efron J, Beer-Gabel M, Wexner SD. The pathology and molecular biology of anal intraepithelial neoplasia: comparisons with cervical and vulvar intraepithelial carcinoma. Int $\mathrm{J}$ Colorectal Dis. 2002;17(4):203-15.

41. Abbasakoor F, Boulos PB. Anal intraepithelial neoplasia. Br J Surg. 2005;92:277-90.
42. D'Souza G, Wiley DJ, Li X, Chmiel JS, Margolick JB, Cranston RD, Jacobson LP. Incidence and epidemiology of anal cancer in the multicenter AIDS cohort study. J Acquir Immune Defic Syndr. 2008;48(4):491-9.

43. Dittmer DP. An appraisal of non-AIDS-defining cancers: comment on "Spectrum of cancer risk late after AIDS onset in the United States". Arch Intern Med. 2010;170(15):1345-6.

44. Joura EA, Giuliano AR, Iversen OE, et al. Broad spectrum HPV vaccine study. A 9-valent HPV vaccine against infection and intraepithelial neoplasia in women. $\mathrm{N}$ Engl $\mathrm{J}$ Med. 2015;372:711-23.

45. Roden $\mathrm{R}, \mathrm{Wu}$ TC. How will HPV vaccines affect cervical cancer? Nat Rev Cancer. 2006;6(10):753-63.

46. Palefsky JM, Giuliano AR, Goldstone S, et al. HPV vaccine against anal HPV infection and anal intraepithelial neoplasia. $\mathrm{N}$ Engl $\mathrm{J}$ Med. 2011;365(17):1576-85.

47. Swedish KA, Factor SH, Goldstone SE. Prevention of recurrent high-grade anal neoplasia with quadrivalent human papillomavirus vaccination of men who have sex with men: a nonconcurrent cohort study. Clin Infect Dis. 2012;54(7):891-8.

48. Villa LL, Costa RL, Petta CA, et al. High sustained efficacy of a prophylactic quadrivalent human papillomavirus types $6 / 11 / 16 / 18$ virus-like particle vaccine through 5 years of follow-up. Br J Cancer. 2006;95:1459-66.

49. Frazer IH, Leggatt GR, Mattarollo SR. Prevention and treatment of papillomavirus-related cancers through immunization. Annu Rev Immunol. 2011;29:111-38.

50. Kenter GG, Welters MJ, Valentijn AR, et al. Vaccination against HPV-16 oncoproteins for vulvar intraepithelial neoplasia. NEJM. 2009;361(19):1838-47.

51. Tinmouth J, Raboud J, Ali M, Malloch L, Su D, Sano M, Lytwyn A, Rourke SB, Rabeneck L, Salit I. The psychological impact of being screened for anal cancer in HIV-infected men who have sex with men. Dis Colon Rectum. 2011;54(3):352-9.

52. Patel J, Salit IE, Berry MJ, de Pokomandy A, Nathan M, Fishman F, Palefsky J, Tinmouth J. Environmental scan of anal cancer screening practices: worldwide survey results. Cancer Med. 2014;3(4):1052-61.

53. Richel O, de Vries HJ, van Noesel CJ, Dijkgraaf MG, Prins JM. Comparison of imiquimod, topical 
fluorouracil, and electrocautery for the treatment of anal intraepithelial neoplasia in HIV-positive men who have sex with men: an open-label, randomised controlled trial. Lancet Oncol. 2013;14(4):346-53.

54. Liszewski W, Ananth AT, Ploch LE, Rogers NE. Anal Pap smears and anal cancer: what dermatologists should know. J Am Acad Dermatol. 2014;71(5):985-92.

55. Dalla Pria A, Alfa-Wali M, Fox P, Holmes P, Weir J, Francis N, Bower M. High-resolution anoscopy screening of HIV-positive MSM: longitudinal results from a pilot study. AIDS. 2014;28(6):861-7.

56. Factor SH, Cooperstein A, Pereira GA, Goldstone SE. Are colon and rectal surgeons ready to screen for anal dysplasia? Results of a survey on attitudes and practice. Sex Transm Dis. 2014;41(4):246-53.

57. Kreimer AR, Brennan P, Lang Kuhs KA, Waterboer T, Clifford G, Franceschi S, et al. Human papillomavirus antibodies and future risk of anogenital cancer: a nested case-control study in the European prospective investigation into cancer and nutrition study. J Clin Oncol. 2015;33(8):877-84.

58. Palefsky JM. Anal squamous intraepithelial lesions in human immunodeficiency virus-positive men and women. Semin Oncol. 2000;27:471-9.

59. Nilsson PJ, Svensson C, Goldman S, Ljungqvist O, Glimelius B. Epidermoid anal cancer: a review of a population-based series of 308 consecutive patients treated according to prospective protocols. Int $\mathrm{J}$ Radiat Oncol Biol Phys. 2005;61(1):92-102.

60. Renehan AG, Saunders MP, Schofield PF, O'Dwyer ST. Patterns of local disease failure and outcome after salvage surgery in patients with anal cancer. $\mathrm{Br}$ J Surg. 2005;92:605-14.

61. Das P, Cantor SB, Parker CL, Zampieri JB, Baschnagel A, Eng C, Delclos ME, Krishnan S, Janjan NA, Crane CH. Long-term quality of life after radiotherapy for the treatment of anal cancer. Cancer. 2010;116(4):822-9.

62. Klas JV, Rothenberger DA, Wong WD, Madoff RD. Malignant tumors of the anal canal: the spectrum of disease, treatment, and outcomes. Cancer. 1999;85(8):1686-93.

63. Lockhart-Mummery HE. Non-venereal lesions of the anal region. Br J Vener Dis. 1963;39:15-7.

64. Greenall MJ, Quan SH, Urmacher C, DeCosse JJ. Treatment of epidermoid carcinoma of the anal canal. Surg Gynecol Obstet. 1985;161(6):509-17.
65. Deniaud-Alexandre E, Touboul E, Tiret E, Sezeur A, Houry S, Gallot D, Parc R, Huang R, Qu SH, Huart J, Pene F, Schlienger M. Results of definitive irradiation in a series of 305 epidermoid carcinomas of the anal canal. Int J Radiat Oncol Biol Phys. 2003;56(5):1259-73.

66. Shepherd NA, Scholefield JH, Love SB, England J, Northover JM. Prognostic factors in anal squamous carcinoma: a multivariate analysis of clinical, pathological and flow cytometric parameters in 235 cases. Histopathology. 1990;16(6):545-55.

67. Das P, Bhatia S, Eng C, Ajani JA, Skibber JM, Rodriguez-Bigas MA, et al. Predictors and patterns of recurrence after definitive chemoradiation for anal cancer. Int $\mathrm{J}$ Radiat Oncol Biol Phys. 2007;68(3):794-800.

68. Goldman S, Svensson C, Bronnergard M, Glimelius B, Wallin G. Prognostic significance of serum concentration of squamous cell carcinoma antigen in anal epidermoid carcinoma. Int J Colorectal Dis. 1993;8(2):98-102.

69. Williams M, Swampilla A, Osborne M, et al. Squamous cell carcinoma antigen (SCCAg); a potentially useful prognostic marker in squamous cell carcinoma of the anal canal and margin (SCCACM). Cancer. 2013;119(13):2391-8.

70. Bertisch B, Franceschi S, Lise M, Vernazza P, Keiser $\mathrm{O}$, Schoni-Affolter $\mathrm{F}$, et al. Risk factors for anal cancer in persons infected with HIV: a nested case-control study in the Swiss HIV Cohort Study. Am J Epidemiol. 2013;178:877-84.

71. Lampejo T, Kavanagh D, Clark J, Goldin R, Osborn M, Ziprin P, Cleator S. Prognostic biomarkers in squamous cell carcinoma of the anus: a systematic review. Br J Cancer. 2010;103:1858-69.

72. Ogunbiyi OA, Scholefield JH, Smith JH, Polacarz SV, Rogers K. Sharp F. Immunohistochemical analysis of p53 expression in anal squamous neoplasia. J Clin Pathol. 1993;46(6):507-12.

73. Lu DW, El-Mofty SK, Wang HL. Expression of p16, Rb, and p53 proteins in squamous cell carcinomas of the anorectal region harboring human papillomavirus DNA. Mod Pathol. 2003;16(7):692-9.

74. Gangopadhyay SAJ, Lin Y, editors. The tumour suppressor gene p53. Frontiers in molecular biology. New York: Oxford University Press; 1997.

75. Mawdsley S, Meadows H, James R, et al. The role of biological molecular markers in predictingboth response to treatment and clinical outcome in squamous cell carcinoma of the anus [abstract 183]. In: ASCO, editors. Proceedings of the ASCO 
2004 Gastrointestinal Cancers Symposium. Alexandria: ASCO; 2004.

76. Ajani JA, Wang $X$, Izzo JG, et al. Molecular biomarkers correlate with disease-free survival in patients with anal canal carcinoma treated with chemoradiation. Dig Dis Sci. 2010;55(4):1098-105.

77. Smaglo BG, Tesfaye A, Halfdanarson TR, Meyer JE, Wang J, Gatalica Z, Reddy S, Arguello D, Boland PM. Comprehensive multiplatform biomarker analysis of 199 anal squamous cell carcinomas. Oncotarget. 2015;6(41):43594-604.

78. Serup-Hansen E, Linnemann D, Skovrider-Ruminski W, Hogdall E, Geertsen PF, Havsteen H. Human papillomavirus genotyping and p16 expression as prognostic factors for patients with American Joint Committee on cancer stages I to III carcinoma of the anal canal. J Clin Oncol. 2014;32:1812-7.

79. Koerber SA, Schoneweg C, Slynko A, Krug D, Haefner MF, Herfarth K, Debus J, Sterzing F, von Knebel Doeberitz M, Prigge ES, Reuschenbach M. Influence of human papillomavirus and p16(INK4a) on treatment outcome of patients with anal cancer. Radiother Oncol. 2014;113:331-6.

80. Meulendijks D, Tomasoa NB, Dewit L, Smits PH, Bakker R, van Velthuysen $\mathrm{ML}$, Rosenberg $\mathrm{EH}$, Beijnen JH, Schellens JH, Cats A. HPV-negative squamous cell carcinoma of the anal canal is unresponsive to standard treatment and frequently carries disruptive mutations in TP53. Br J Cancer. 2015;112:1358-66.

81. Baricevic I, He X, Chakrabarty B, Olive AW, Bailey C, Summers J, Hampson L, Hampson I, Gilbert DC, Renehan AG. High-sensitivity human papilloma virus genotyping reveals near universal positivity in anal squamous cell carcinoma: different implications for vaccine prevention and prognosis. Eur J Cancer. 2015;51:776-85.

82. Gilbert DC, Williams A, Allan K, et al. p16INK4A, p53, EGFR expression and KRAS mutation status in squamous cell cancers of the anus: correlation with outcomes following chemo-radiotherapy. Radiother Oncol. 2013;109(1):146-51.

83. Rodel F, Wieland U, Fraunholz I, Kitz J, Rave-Frank M, Wolff HA, Weiss C, Wirtz R, Balermpas P, Fokas E, Rodel C. Human papillomavirus DNA load and p16INK4a expression predict for local control in patients with anal squamous cell carcinoma treated with chemoradiotherapy. Int $\mathrm{J}$ Cancer. 2014;136:278-88.

84. Mai S, Welzel G, Ottstadt M, Lohr F, Severa S, Prigge ES, Wentzensen $\mathrm{N}$, Trunk MJ, Wenz F, von Knebel-Doeberitz M, Reuschenbach M. Prognostic relevance of HPV infection and p16 overexpression in squamous cell anal cancer. Int J Radiat Oncol Biol Phys. 2015;93(4):819-27.

85. Huang SH, Waldron JN, Milosevic $M$, Shen $X$, Ringash J, Su J, et al. Prognostic value of pretreatment circulating neutrophils, monocytes, and lymphocytes in oropharyngeal cancer stratified by human papillomavirus status. Cancer. 2015;121(4):545-55.

86. Toh E, Wilson J, Seabg-Montefiore D, Boterill I. Neutrophil:lymphocyte ratio as a simple and novel biomarker for prediction of locoregional recurrence after chemoradiotherapy for squamous cell carcinoma of the anus. Colorectal Dis. 2014;16(3):O90-7.

87. Gilbert DC, Serup-Hansen E, Linnemann D, Høgdall E, Bailey C, Summers J, Havsteen H, Thomas GJ. Tumour-infiltrating lymphocyte scores effectively stratify outcomes over and above p16 post chemo-radiotherapy in anal cancer. Br J Cancer. 2016;114(2):134-7. doi:10.1038/bjc.2015.448.

88. Edge SB, Byrd DR, Compton CC, Fritz AG, Greene FI, Trotti AI. AJCC cancer staging manual. New York: Springer; 2009.

89. Koh DM, Dzik-Jurasz A, O’Neill B, Tait D, Husband JE, Brown G. Pelvic phased-array MR imaging of anal carcinoma before and after chemoradiation. $\mathrm{Br}$ J Radiol. 2008;81(962):91-8.

90. Bhuva NJ, Glynne-Jones R, Sonoda L, Wong WL, Harrison MK. To PET or not to PET? That is the question. Staging in anal cancer. Ann Oncol. 2012;23(8):2078-82.

91. De La Rochefordière A, Pontvert D, Asselain B, Fenton J, Alapetite C, Girodet J. Radiothérapie des cancers du canal anal. Expérience de l'institut Curie dans le traitement des aires ganglionnaires. Bull Cancer Radiother. 1993;80:391-8.

92. Gerard JP, Chapet O, Samiei F, Morignat E, Isaac S, Paulin C, Romestaing P, Favrel V, Mornex F, Bobin JY. Management of inguinal lymph node metastases in patients with carcinoma of the anal canal: experience in a series of 270 patients treated in Lyon and review of the literature. Cancer. 2001;92(1):77-84.

93. Damin DC, Rosito MA, Schwartzmann G. Sentinel lymph node in carcinoma of the anal canal: a review. Eur J Surg Oncol. 2006;32:247-52.

94. Mistrangelo M, Pelosi E, Bellò M, Ricardi U, Milanesi E, Cassoni P, Baccega $\mathrm{M}$, et al. Role of positron emission tomography-computed tomography in the management of anal cancer. Int J Radiat Oncol Biol Phys. 2012;84(1):66-72. 
95. De Jong JS, Beukema JC, Van Dam GM, Slart R, Lemstra C, Wiggers $T$, et al. Limited value of staging squamous cell carcinoma of the anal margin and canal using the sentinel node lymph node procedure: prospective study with long term follow up. Am Surg Oncol. 2010;17:2656-62.

96. Sebag-Montefiore D, James R, Meadows H. The pattern and timing of disease recurrence in squamous cancer of the anus: mature results from the NCRI ACT II trial. J Clin Oncol. 2012;30 (suppl; abstr 4029).

97. Hwang JM, Rao AR, Cosmatos HA, Wang R, Kaptein JS, Kagan RA, HsiangJY, Tome M. Treatment of T3 and T4 anal carcinoma with combined chemoradiation and interstitial 192Ir implantation: a 10-year experience. Brachytherapy. 2004;3(2):95-100.

98. Kachnic LA, Winter K, Myerson RJ, et al. RTOG 0529: a phase 2 evaluation of dose-painted intensity modulated radiation therapy in combination with 5-fluorouracil and mitomycin-C for the reduction of acute morbidity in carcinoma of the anal canal. Int J Radiat Oncol Biol Phys. 2013;86(1):27-33.

99. Matzinger O, Roelofsen F, Mineur L, Koswig S, Van Der Steen-Banasik EM, Van Houtte P, Haustermans $\mathrm{K}$, Radosevic-Jelic L, Mueller RP, Maingon P, Collette L, Bosset JF. Mitomycin C with continuous fluorouracil or with cisplatin in combination with radiotherapy for locally advanced anal cancer (European Organisation for Research and Treatment of Cancer phase II study 22011-40014). Eur J Cancer. 2009;45(16):2782-91.

100. Bosset JF, Roelofsen F, Morgan DA, Budach V, Coucke P, Jager JJ, Van der Steen-Banasik E, Triviere N, Stuben G, Puyraveau M, Mercier M. Shortened irradiation scheme, continuous infusion of 5-fluorouracil and fractionation of mitomycin $\mathrm{C}$ in locally advanced anal carcinomas. Results of a phase II study of the European Organization for Research and Treatment of Cancer. Radiotherapy and Gastrointestinal Cooperative Groups. Eur J Cancer. 2003;39(1):45-51.

101. Glynne-Jones R, Meadows H, Wan S, Gollins S, Leslie M, Levine E, McDonald AC, Myint S, Samuel L, Sebag-Montefiore D. EXTRA-a multicenter phase II study of chemoradiation using a 5 day per week oral regimen of capecitabine and intravenous mitomycin C in anal cancer. Int J Radiat Oncol Biol Phys. 2008;72(1):119-26.

102. Deenen MJ, Dewit L, Boot H, Beijnen JH, Schellens $\mathrm{JH}$, Cats A. Simultaneous integrated boost-intensity modulated radiation therapy with concomitant capecitabine and mitomycin $\mathrm{C}$ for locally advanced anal carcinoma: a phase 1 study. Int J Radiat Oncol Biol Phys. 2013;85(5):e201-7.
103. Oliveira SC, Moniz CM, Riechelmann R, Alex AK, Braghirolli MI, Bariani G, Nahas C, Hoff PM. Phase II study of capecitabine in substitution of 5-FU in the chemoradiotherapy regimen for patients with localized squamous cell carcinoma of the anal canal. J Gastrointest Cancer. 2016;47(1):75-81.

104. Thind G, Johal B, Follwell M, Kennecke HF. Chemoradiation with capecitabine and mitomycin-C for stage I-III anal squamous cell carcinoma. Radiat Oncol. 2014;29(9):124.

105. Wan DDC, Schellenberg D, Hay J, et al. A comparison between 5-fluorouracil/mitomycin (FM) and capecitabine/mitomycin (CM) in combination with radiation (RT) for squamous cell carcinoma (SCC) of the anal canal. J Clin Oncol. 2014;32:5s (suppl; abstr 4031).

106. Martenson JA, Lipsitz SR, Wagner H Jr, Kaplan EH, Otteman LA, Schuchter LM, Mansour EG, Talamonti MS, Benson AB 3rd. Initial results of a phase II trial of high dose radiation therapy, 5-fluorouracil, and cisplatin for patients with anal cancer (E4292): an Eastern Cooperative Oncology Group study. Int J Radiat Oncol Biol Phys. 1996;35(4):745-9.

107. Peiffert D, Giovannini M, Ducreux M, Michel $P$, Francois E, Lemanski C, Mirabel X, Cvitkovic F, Luporsi E, Conroy T, Gerard JP. High-dose radiation therapy and neoadjuvant plus concomitant chemotherapy with 5-fluorouracil and cisplatin in patients with locally advanced squamous-cell anal canal cancer: final results of a phase II study. Ann Oncol. 2001;12(3):397-404.

108. Gerard JP, Ayzac L, Hun D, Romestaing P, Coquard $\mathrm{R}$, Ardiet JM, Mornex F. Treatment of anal canal carcinoma with high dose radiation therapy and concomitant fluorouracil-cisplatinum. Long-term results in 95 patients. Radiother Oncol. 1998;46(3):249-56.

109. Doci R, Zucali R, Bombelli L, Montalto F, Lamonica G. Combined chemoradiation therapy for anal cancer. A report of 56 cases. Ann Surg. 1992;215(2):150-6.

110. Hung A, Crane C, Delclos M, Ballo M, Ajani J, Lin E, Feig B, Skibber J, Janjan N. Cisplatin-based combined modality therapy for anal carcinoma: a wider therapeutic index. Cancer. 2003;97(5):1195-202.

111. Olivatto LO, Cabral V, Rosa A, Bezerra M, Santarem E, Fassizoli A, Castro L, Simões JH, Small IA, Ferreira CG. Mitomycin-C- or cisplatin-based chemoradiotherapy for anal canal carcinoma: long-term results. Int $\mathrm{J}$ Radiat Oncol Biol Phys. 2011;79(2):490-5. 
112. Eng C, Chang GJ, Das P, et al. Phase II study of capecitabine and oxaliplatin with concurrent radiation therapy (XELOX-XRT) for squamous cell carcinoma of the anal canal. J Clin Oncol 2009;27:15S (abstr 4116).

113. Meropol NJ, Niedzwiecki D, Shank B, Colacchio TA, Ellerton J, Valone F, Budinger S, Day JM, Hopkins J, Tepper J, Goldberg RM, Mayer RJ. Induction therapy for poor-prognosis anal canal carcinoma: a phase II study of the Cancer and Leukemia Group B (CALGB 9281). J Clin Oncol. 2008;26(19):3229-34.

114. Sebag-Montefiore D, Meadows HM, Cunningham D, Plowman PN, Hurman DC, Davidson N, Grieve R, Levine E, Glynne-Jones R. Three cytotoxic drugs combined with pelvic radiation and as maintenance chemotherapy for patients with squamous cell carcinoma of the anus (SCCA): long-term follow-up of a phase II pilot study using 5-fluorouracil, mitomycin $\mathrm{C}$ and cisplatin. Radiother Oncol. 2012;104(2):155-60.

115. Ortholan C, Ramaioli A, Peiffert D, Lusinchi A, Romestaing P, Chauveinc L, Touboul E, Peignaux K, Bruna A, de La Roche G, Lagrange JL, Alzieu C, Gerard JP. Anal canal carcinoma: early-stage tumors $\leq 10 \mathrm{~mm}$ (T1 or Tis): therapeutic options and original pattern of local failure after radiotherapy. Int $\mathrm{J}$ Radiat Oncol Biol Phys. 2005;62(2):479-85.

116. Karia PS, Jambusaria-Pahlajani A, Harrington DP, Murphy GF, Qureshi AA, Schmults CD. Evaluation of American Joint Committee on Cancer, International Union Against Cancer, and Brigham and Women's Hospital tumor staging for cutaneous squamous cell carcinoma. J Clin Oncol. 2014;32(4):327-34.

117. Hatfield P, Cooper R, Sebag-Montefiore D. Involved-field, low-dose chemoradiotherapy for early-stage anal carcinoma. Int J Radiat Oncol Biol Phys. 2008;70:419-24.

118. Hu K, Minsky BD, Cohen AM, Kelsen DP, Guillem JG, Paty PP, et al. 30 Gy may be an adequate dose in patients with anal cancer treated with excisional biopsy followed by combined-modality therapy. J Surg Oncol. 1999;70:71-7.

119. Tanum G, Holm R. Anal carcinoma: a clinical approach to p53 and RB gene proteins. Oncology. 1996;53(5):369-73.

120. Schwarz JK, Siegel BA, Dehdashti F, Myerson RJ, Fleshman JW, Grigsby PW. Tumor response and survival predicted by post-therapy FDG-PET/CT in anal cancer. Int $\mathrm{J}$ Radiat Oncol Biol Phys. 2008;71(1):180-6.
121. Glynne-Jones R, James $\mathrm{R}$, Meadows $\mathrm{H}$, et al. Optimum time to assess complete clinical response (CR) following chemoradiation (CRT) using mitomycin (MMC) or cisplatin (CisP), with or without maintenance $\mathrm{CisP} / 5 \mathrm{FU}$ in squamous cell carcinoma of the anus: results of ACT II. J Clin Oncol 2012;30 (suppl; abstr 4004).

122. Renehan AG, O'Dwyer ST. Management of local disease relapse. Colorectal Dis. 2011;13(s1):44-52.

123. Lefevre JH, Corte H, Tiret E, Boccara D, Chaouat M, Touboul E, et al. Abdominoperineal resection for squamous cell anal carcinoma: survival and risk factors for recurrence. Ann Surg Oncol. 2012;19:4186-92.

124. Correa JHS, Castro LS, Kesley R, Dias JA, Olivatto LO, Martins IO, Lopasso FP. Salvage abdominoperineal resection for anal cancer following chemoradiation: a proposed scoring system for predicting postoperative survival. J Surg Oncol. 2013;107(5):486-92.

125. Harris DA, Williamson J, Davies M, Evans MD, Drew P, Beynon J, Swansea Pelvic Oncology Group. Outcome of salvage surgery for anal squamous cell carcinoma. Colorectal Dis. 2013;15(8):968-73.

126. Chauveinc L, Buthaud X, Falcou MC, Mosseri V, De la Rochefordiere A, Pierga JY, Girodet J, Salmon RJ. Anal canal cancer treatment: practical limitations of routine prescription of concurrent chemotherapy and radiotherapy. Br J Cancer. 2003;89(11):2057-61.

127. Allal AS, Mermillod B, Roth AD, Marti MC, Kurtz JM. Impact of clinical and therapeutic factors on major late complications after radiotherapy with or without concomitant chemotherapy for anal carcinoma. Int $\mathrm{J}$ Radiat Oncol Biol Phys. 1997;39(5):1099-105.

128. Benton B, Norton C, Linday JO, et al. Can nurses manage gastrointestinal symptoms arising from pelvic radiation disease? Clinical Oncology. 2011;23(8):538-51.

129. Dunberger G, Bergmark K. Nurse-led care for the management of side effects of pelvic radiotherapy: what does it achieve? Curr Opin Support Palliat Care. 2012;6(1):60-68.

130. Slevin ML, Plowman PN, Ryan CM et al. Chemoradiotherapy for anal cancer improves quality of life compared to radiotherapy alone. J Clin Oncol. 1998;17 (abstract 266).

131. Tournier-Rangeard L, Mercier M, Peiffert D, Gerard JP, Romestaing P, Lemanski C, Mirabel X, Pommier P, Denis B. Radiochemotherapy of locally advanced anal canal carcinoma: prospective assessment of 
early impact on the quality of life (randomized trial ACCORD 03). Radiother Oncol. 2008;87(3):391-7.

132. Knowles G, Haigh R, McLean C, Phillips H. Late effects and quality of life after chemo-radiation for the treatment of anal cancer. Eur J Oncol Nurs. 2015;19(5):479-85.

133. Vordermark D, Sailer M, Flentje M, et al. Curative intent radiation therapy in anal carcinoma: quality of life and sphincter control. Radiother Oncol. 1999;52:239-43.

134. Vordermark D, Sailer M, Flentje M, Thiede A, Kolbl O. Impaired sphincter function and good quality of life in anal carcinoma patients after radiotherapy: a paradox? Front Radiat Ther Oncol. 2002;37:132-9.

135. Sodergren SC, Vassiliou V, Dennis K, Tomaszewski KA, Gilbert A, Glynne-Jones R, Nugent K, Sebag-Montefiore D, Johnson CD, EORTC Quality of Life Group. Systematic review of the quality of life issues associated with anal cancer and its treatment with radiochemotherapy. Support Care Cancer. 2015;23(12):3613-23.

136. Lépinoy A, Lescut N, Puyraveau M, Caubet M, Boustani J, Lakkis Z, et al. Evaluation of a $36 \mathrm{~Gy}$ elective node irradiation dose in anal cancer. Radiother Oncol. 2015;116(2):197-201.

137. Moreau-Claeys MV, Peiffert D. Normal tissue tolerance to external beam radiation therapy: anal canal. Cancer Radiother. 2010;14(4-5):359-62.

138. Salama JK, Mell LK, Schomas DA, Miller RC, Devisetty K, Jani AB, Mundt AJ, Roeske JC, Liauw SL, Chmura SJ. Concurrent chemotherapy and intensity-modulated radiation therapy for anal canal cancer patients: a multicenter experience. J Clin Oncol. 2007;25(29):4581-6.

139. Mell LK, Schomas DA, Salama JK, Devisetty K, Aydogan B, Miller RC, Jani AB, Kindler HL, Mundt AJ, Roeske JC, Chmura SJ. Association between bone marrow dosimetric parameters and acute hematologic toxicity in anal cancer patients treated with concurrent chemotherapy and intensity-modulated radiotherapy. Int $\mathrm{J}$ Radiat Oncol Biol Phys. 2008;70(5):1431-7.

140. Alvarez G, Perry A, Tan BR, Wang HL. Expression of epidermal growth factor receptor in squamous cell carcinomas of the anal canal is independent of gene amplification. Mod Pathol. 2006;19(7):942-9.

141. Van Damme N, Deron P, Van Roy N, Demetter P, Bols A, Van Dorpe J, Baert F, Van Laethem JL, Speleman F, Pauwels P, Peeters M. Epidermal growth factor receptor and K-RAS status in two cohorts of squamous cell carcinomas. BMC Cancer. 2010;10:189.
142. Martin V, Zanellato E, Franzetti-Pellanda A, Molinari F, Movilia A, Paganotti A, et al. EGFR, KRAS, BRAF, and PIK3CA characterization in squamous cell anal cancer. Histol Histopathol. 2014;29(4):513-21.

143. Zampino MG, Magni E, Sonzogni A, Renne G. K-ras status in squamous cell anal carcinoma (SCC): it's time for target-oriented treatment? Cancer Chemother Pharmacol. 2009;65:197-9.

144. Paliga A, Onerheim R, Gologan A, et al. EGFR and $\mathrm{K}$-ras gene mutation status in squamous cell anal carcinoma: a role for concurrent radiation and EGFR inhibitors? Br J Cancer. 2012;107:1864-8.

145. Casadei Gardini A, Capelli L, Ulivi P, et al. KRAS, BRAF and PIK3CA status in squamous cell anal carcinoma (SCAC). PLoS One. 2014;9(3):e92071.

146. Serup-Hansen E, Linnemann D, Høgdall E, Geertsen PF, Havsteen H. KRAS and BRAF mutations in anal carcinoma. APMIS. 2015;123(1):53-9.

147. Huang SM, Harari PM. Modulation of radiation response after epidermal growth factor receptor blockade in squamous cell carcinomas: inhibition of damage repair, cell cycle kinetics, and tumor angiogenesis. Clin Cancer Res. 2000;6(6):2166-74.

148. Bussink J, van der Kogel AJ, Kaanders JH. Activation of the PI3-K/AKT pathway and implications for radioresistance mechanisms in head and neck cancer. Lancet Oncol. 2008;9(3):288-96.

149. Miyaguchi M, Olofsson J, Hellquist HB. Expression of epidermal growth factor receptor in glottic carcinoma and its relation to recurrence after radiotherapy. Clin Otolaryngol Allied Sci. 1991;16(5):466-9.

150. Bonner JA, et al. Radiotherapy plus cetuximab for squamous cell carcinoma of the head and neck. N Engl J Med. 2006;354:567-78.

151. Olivatto LO, Vieira FM, Pereira BV, Victorino AP, Bezerra M, Araujo CM, Erlich F, Faroni L, Castro L, Lusis EC, Marins A, Ferreira CG. Phase 1 study of cetuximab in combination with 5-fluorouracil, cisplatin, and radiotherapy in patients with locally advanced anal canal carcinoma. Cancer. 2013;119(16):2973-80.

152. Deutsch E, Lemanski C, Pignon JP, et al. Unexpected toxicity of cetuximab combined with conventional chemoradiotherapy in patients with locally advanced anal cancer: results of the UNICANCER ACCORD 16 phase II trial. Ann Oncol. 2013;24:2834-8.

153. Garg M, Lee JY, Kachnic LA, et al. Phase II trials of cetuximab (CX) plus cisplatin (CDDP), 
5-fluorouracil (5-FU) and radiation (RT) in immunocompetent (ECOG 3205) and HIV-positive (AMC045) patients with squamous cell carcinoma of the anal canal (SCAC): safety and preliminary efficacy results (abstract 4030). In: ASCO, editors. ASCO Annual Meeting Proceedings 2012. Alexandria: ASCO; 2012.

154. Leon O, Guren MG, Radu C, et al. Phase I study of cetuximab in combination with 5-fluorouracil, mitomycin $\mathrm{C}$ and radiotherapy in patients with locally advanced anal cancer. Eur J Cancer. 2015;51(18):2740-6.

155. Patel H, Polanco-Echeverry G, Segditsas S, Volikos E, McCart A, Lai C, Guenther T, Zaitoun A, Sieber O, Ilyas M, Northover J, Silver A. Activation of AKT and nuclear accumulation of wild type TP53 and MDM2 in anal squamous cell carcinoma. Int $\mathrm{J}$ Cancer. 2007;121(12):2668-73.

156. D’Incecco A, Andreozzi M, Ludovini V, et al. PD-1 and PD-L1 expression in molecularly selected non-small-cell lung cancer patients. Br J Cancer. 2015;112:95-102.

157. Gujja S, Williamson SK, Batra A et al. Programmed cell death-ligand 1 (PD-L1) expression and outcome in patients with squamous cell cancer of anal canal (SCCAC). J Clin Oncol. 2015;33 (suppl; abstr 3523).

158. Ott $\mathrm{P}$ et al. Pembrolizumab (MK-3475) for PD-L1-positive squamous cell carcinoma (SCC) of the anal canal: preliminary safety and efficacy results from KEYNOTE-028. Ann Oncol. 2015 (abstr \#500).

159. Postow MA, Callahan MK, Barker CA, et al. Immunologic correlates of the abscopal effect in a patient with melanoma. $\mathrm{N}$ Engl J Med. 2012;366:925-31.

160. Golden EB, Demaria S, Schiff PB, Chachoua A, Formenti SC. An abscopal response to radiation and ipilimumab in a patient with metastatic non-small cell lung cancer. Cancer Immunol Res. 2013;1:365-72.

161. Rubio CA, Nilsson PJ, Petersson F, Hoog A, Blegen $\mathrm{H}$, Chetty R. The clinical significance of massive intratumoral lymphocytosis in squamous cell carcinoma of the anus. Int J Clin Exp Pathol. 2008;1:376-80.

162. Illidge T. Turning radiotherapy into an effective systemic anti-cancer treatment in combination with immunotherapy. Clin Oncol (R Coll Radiol). 2015;27(12):696-9.

163. Stanley M. Immune responses to human papillomavirus. Vaccine. 2006;30(24 Suppl 1):S16-22.

164. Caberg JH, Hubert PM, Begon DY, Herfs MF, Roncarati PJ, Boniver JJ, et al. Silencing of E7 oncogene restores functional E-cadherin expression in human papillomavirus 16-transformed keratinocytes. Carcinogenesis. 2008;29(7):1441-7.

165. Cory L, Chu C. ADXS-HPV: a therapeutic Listeria vaccination targeting cervical cancers expressing the HPV E7 antigen. Hum Vaccin Immunother. 2014;10(11):3190-5.

166. Petit RG, Basu P. ADXS11-001 immunotherapy targeting HPV-E7: updated survival and safety data from a phase 2 study in Indian women with recurrent/refractory cervical cancer. J Immunother Cancer. 2013;1(1):1.

167. Basu P, Mehta AO, et al. ADXS11-001 immunotherapy targeting HPV-E7: final results from a phase 2 study in Indian women with recurrent cervical cancer. American Society of Clinical Oncology (ASCO) Annual Meeting, May 30-June 3, 2014; Chicago, Illinois, USA. J Clin Oncol. 2014;32:5s (suppl; abstr 5610).

168. Bendell JC, Eng C, Moore KN et al. Checkpoint kinase (CHK) 1/2 inhibitor LY2606368 in a phase I, dose-expansion study in patients (pts) with metastatic squamous cell carcinoma (mSCC) of the anus. J Clin Oncol. 2015;33 (suppl; abstr 3520).

169. Levy A, Azria D, Pignon JP, et al. Low response rate after cetuximab combined with conventional chemoradiotherapy in patients with locally advanced anal cancer: long-term results of the UNICANCER ACCORD 16 phase II trial. Radiother Oncol. 2015;114(3):415-6. 